Estudios sobre armas antiguas, arte militar $\mathrm{y}$ vida cultural en oriente y occidente XXIX (2009), pp. 7-38 ISSN: 0436-029X

\title{
EL DEPÓSITO DE ARMAS DEL BRONCE FINAL DE «LOS CASCAJOS», GRAÑÓN (LA RIOJA)
}

\author{
THE LATE BRONZE AGE WEAPON HOARD FROM «LOS CASCAJOS», \\ GRAÑÓN (LA RIOJA, SPAIN)
}

POR

\author{
CARmen Alonso FernándeZ y JaVier JimÉnEZ ECheVARRÍA
}

\section{RESUMEN - ABstract}

El hasta ahora inédito depósito de armas de «Los Cascajos» es excepcional dentro de su contexto geográfico, ya que es el único recuperado en la provincia de La Rioja, pero también a nivel peninsular por las piezas que lo integran: por su número, tipología, origen y conservación. Se trata de un conjunto de metales del tránsito del BFI al BFII (1200-1000 a.C.), algunos de ellos inéditos en la Península, ya que no son de factura local, sino importados de otros territorios del Bronce Atlántico. Las características formales de algunas piezas señalan el Valle del Támesis como lugar de procedencia, aunque sin descartar el origen galo de otras.

The until now unpublished hoard of weapons from «Los Cascajos» is exceptional in its geographical context, since it is the only one recovered in the province of La Rioja, and it is also exceptional at the Peninsular level for the pieces that make it up: number, typology, origin and conservation. It's a set of metal pieces from the transit of the Late Bronze Age I to the Late Bronze Age II (1200-1000 B.C.), some of them unpublished in the Peninsula, since they are not of local manufacture but imported from other territories of the Atlantic Bronze Age. The formal characteristics of some pieces point to the Thames Valley as place of origin, although it is not possible to dismiss the Gallic origin of others.

\section{Palabras Clave - Keywords}

Depósito; armas; Bronce Atlántico; La Rioja; espada; punta de lanza; metalurgia.

Hoard; arms; Atlantic Bronze Age; La Rioja; sword; point of spear; metallurgy.

\section{INTRODUCCIÓN}

En el año 2007 fueron entregadas a la Dirección General de Patrimonio del Gobierno de La Rioja un conjunto de armas de bronce recuperadas en una parcela del municipio riojano de Grañón ${ }^{1}$ (fig. 0). Sorprendentemente, los hallazgos se iniciaron hace unos cuarenta años y han

* CRONOS S. C. Arqueología y Patrimonio, Centro Europeo de Empresas e Innovación, Módulo 3. Aeropuerto de Burgos. 09007 Burgos. E-mail: tecnicos@cronossc.es

1 Este estudio de materiales ha sido realizado dentro de los trabajos arqueológicos integrados en la construcción de la Autovía A-12 «Camino de Santiago», llevados a cabo por la empresa CRONOS S. C., con financiación del Ministerio de Fomento. La restauración y el estudio arqueometalúrgico de las piezas ha corrido a cargo del Gobierno de La Rioja. El dibujo arqueológico ha sido realizado por Belén Alonso (CRONOS S. C.). 
continuado en pequeñas cantidades hasta hace aproximadamente diez. El primer descubrimiento, y el más voluminoso, lo protagonizó el padre de los donantes, D. Vicente Murillo Murillo, cuando durante las labores de cultivo la reja del arado topó con numerosos objetos de bronce depositados en forma de «enrejado» o «emparrillado» acompañado de abundante ceniza.

Al parecer, según testimonio de los donantes, la colección de piezas extraída en este primer momento, que fue vendida casi en su totalidad a un chatarrero, pesaba más de $50 \mathrm{~kg}$, y estaba integrada por espadas, lanzas, yelmos, escudos, fíbulas y placas de cinturón. Con el transcurso del

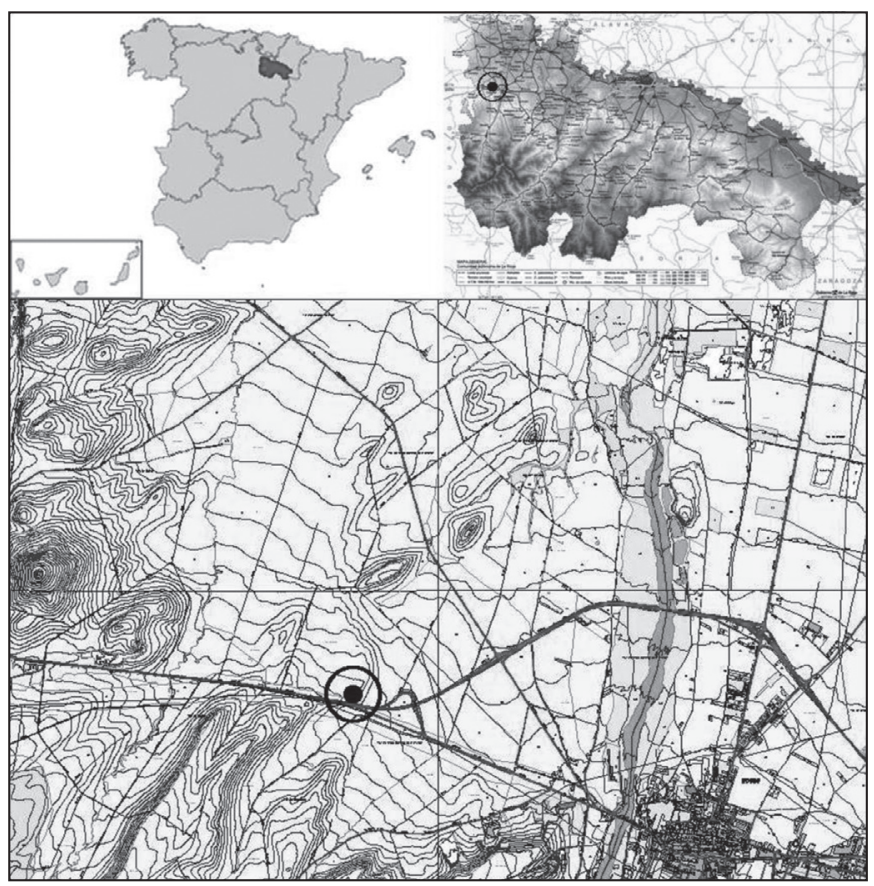
tiempo la colección se ha ido dispersando, y en la actualidad únicamente han sido recuperados dieciocho objetos, de los que solo tres son piezas completas (fig. 1).

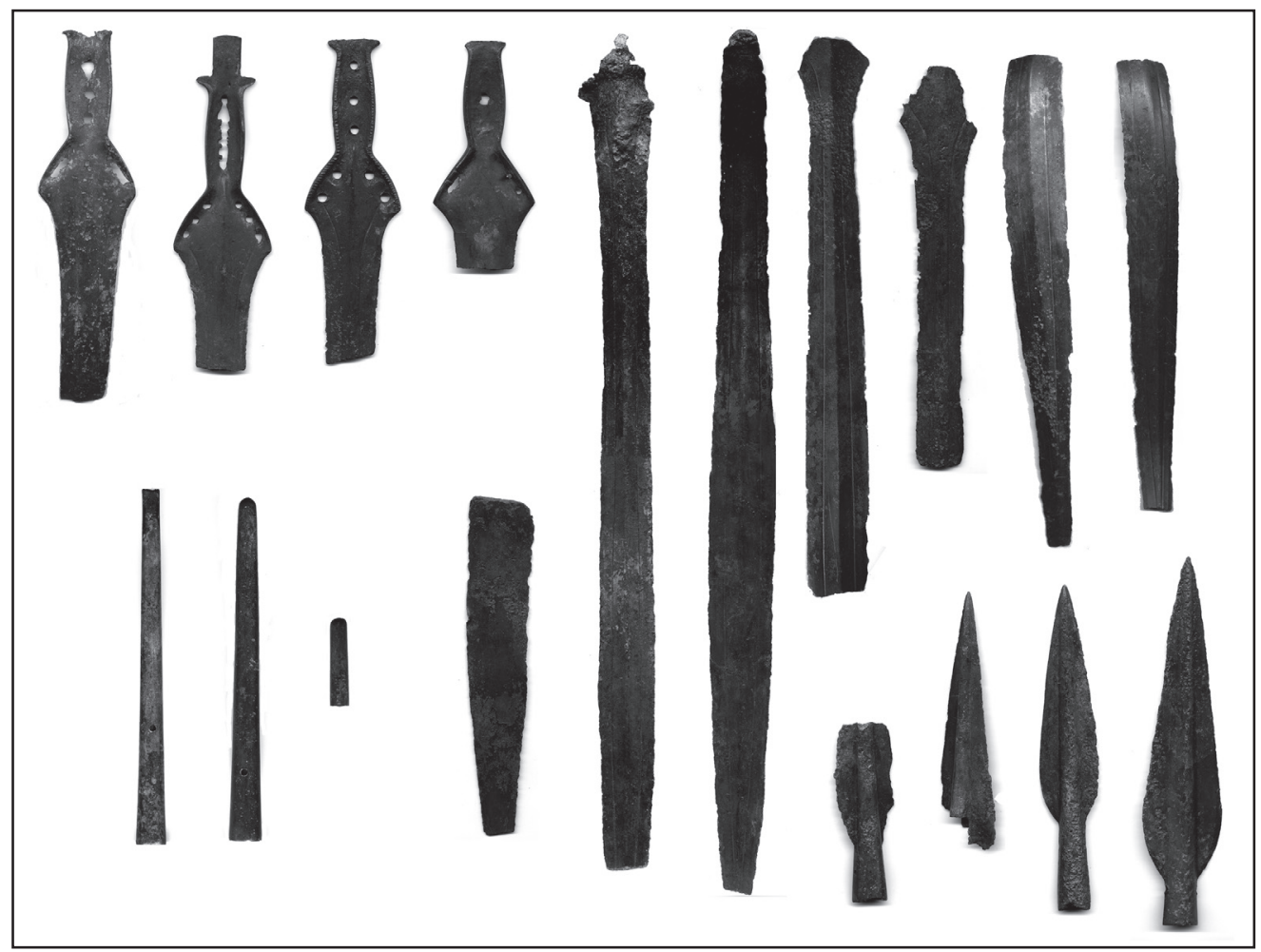

Figura 1. Depósito de armas de «Los Cascajos», Grañón (La Rioja). 


\section{2. ÁMBITO GEOGRÁFICO Y ARQUEOLÓGICO}

El depósito fue localizado en las proximidades de la triple mojonera de los municipios riojanos de Grañón, Santo Domingo de La Calzada y Corporales; en la ladera sureste de una amplia loma situada a $670 \mathrm{~m}$ de altitud sobre el nivel del mar, que paulatinamente desciende hasta la terraza y curso del río Oja. Este emplazamiento cuenta con un destacado dominio visual sobre la vega del río, del que dista $2500 \mathrm{~m}$ de su margen izquierda.

En el ámbito del lugar del hallazgo se localiza el yacimiento arqueológico «Los Cascajos», un poblado ganadero de carácter seminómada o trasterminante enmarcado culturalmente en la transición entre el Cobre Tardío/Final y la Edad de Bronce. La excavación arqueológica del yacimiento ha permitido esclarecer que el pastoreo se realizaba con bóvidos y ovicápridos. La actividad ganadera estaría asociada a la existencia de rutas pecuarias, que también surcaron este territorio durante la Edad Media, conservándose una de ellas hasta hace pocas décadas en las cercanías del lugar de hallazgo. Esta vía, denominada «camino de la Dehesa», finalizaba su andadura en las proximidades del lugar del depósito, donde entroncaba con la carretera N-120, actual autovía A-12.

Precisamente buena parte del trayecto de esta importante vía de comunicación, que une las ciudades de Logroño y Burgos, está trazado siguiendo la antigua caminería romana. En el ámbito que nos ocupa coincide con la vía Monasterio de Rodilla a Nájera que, tras pasar por Grañón, se une a pocos kilómetros con la vía de Asturica a Caesaraugusta (Abásolo, 1975: 207-210). Además, a su paso por el yacimiento «Los Cascajos», la vía viene a coincidir con el Camino de Santiago, fijado definitivamente por La Rioja Alta por Sancho el Mayor (10041038). A pie del camino jacobeo, a unos $200 \mathrm{~m}$ del lugar donde fue recuperado el depósito, recientemente han sido descubiertos restos arqueológicos relacionados con un edificio cultual con necrópolis asociada de cronología bajomedieval, relacionados con la existencia de un hospital de peregrinos o de un pequeño despoblado. En ese lugar, una cruz conmemora una antigua disputa entre Grañón y Santo Domingo de la Calzada, de posible raigambre medieval, fijando un territorio de frontera.

Por lo tanto, el singular depósito broncíneo fue localizado a pie de un importante punto de paso, constatado como corredor natural, y ruta ganadera y comercial desde la Prehistoria reciente hasta la actualidad.

\section{ESPADAS PISTILIFORMES DE PUÑO TRIPARTITO}

\subsection{INVENTARIO}

\section{N. ${ }^{o}$ 1: Empuñadura (fig. 2)}

Tipometría: longitud máxima: $227 \mathrm{~mm}$; longitud de la hoja: $103 \mathrm{~mm}$; anchura máxima: 59 mm; grosor máximo: $9 \mathrm{~mm}$; peso: $245 \mathrm{~g}$.

Lengüeta con guarda en forma de «U» cerrada. El huso es ovalado y, aunque el extremo distal de la empuñadura está fragmentado, se aprecia que estaba rematado con dos apéndices, por lo que pudo contar con la clásica lengüetilla de las empuñaduras tipo Erbenheim. Cuenta con tres perforaciones para roblones en la zona central del huso, para la sujeción al pomo, y otros cuatro, dos a dos, en la guarda, con apariencia de calado debido al deterioro.

La hoja, de sección romboidal roma, cuenta con nervio central resaltado jalonado por doble incisión. Tiene levemente insinuado el ricassos, decorado a su vez con finas incisiones. 

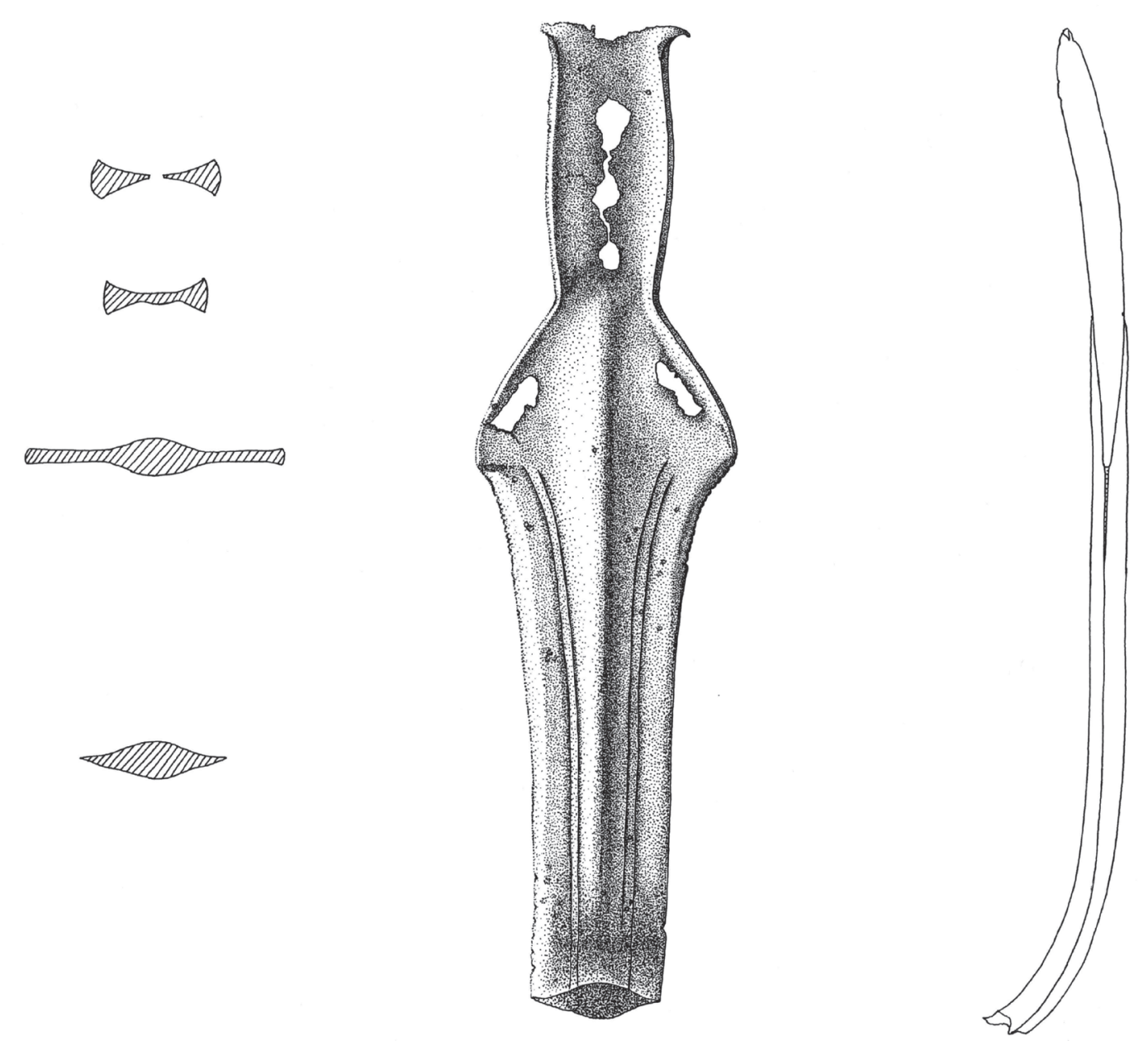

Figura 2. Empuñadura de espada n. ${ }^{\circ} 1$.

N. ${ }^{\circ}$ 2: Empuñadura (fig. 3)

Tipometría: longitud máxima: $189 \mathrm{~mm}$; longitud de la hoja: $71 \mathrm{~mm}$; anchura máxima: 61 mm; grosor máximo: $9 \mathrm{~mm}$.

Empuñadura con guarda en forma de «U» cerrada. El pomo está rematado por dos apéndices, y el huso, ovalado, cuenta con tres perforaciones para albergar los roblones. La guarda presenta otros cuatro agujeros para roblones, dos a cada lado. La rugosa terminación del pomo podría deberse a la fractura de la lengüetilla clásica de las empuñaduras tipo Erbenheim.

La hoja, de sección romboidal, cuenta con nervio central bien resaltado, flanqueado a cada lado por una incisión que se prolonga hasta las perforaciones de la guarda. La arista de la unión de la lengüeta con la hoja está decorada con finas muescas, insinuándose las escotaduras o ricassos. Los bordes de la lengüeta también están decorados mediante la sucesión de muescas. 


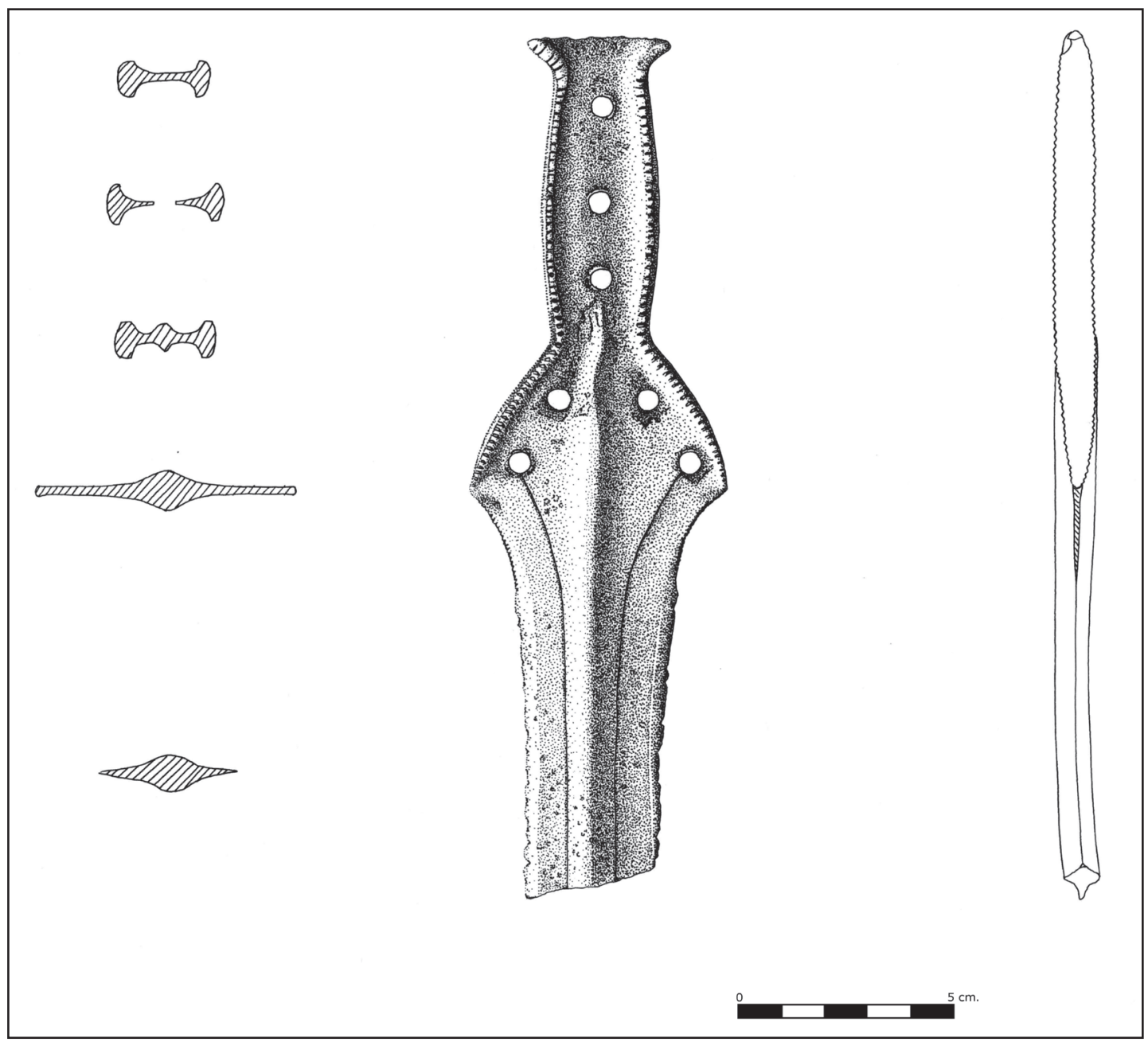

Figura 3. Empuñadura de espada n. ${ }^{\circ} 2$.

\section{N. ${ }^{\circ}$ 3/10: Empuñadura y fragmento de hoja (fig. 4)}

Tipometría de la empuñadura: longitud máxima: $138 \mathrm{~mm}$; longitud de la hoja: $23 \mathrm{~mm}$; anchura máxima: $61 \mathrm{~mm}$; grosor máximo: $9 \mathrm{~mm}$; peso: $175 \mathrm{~g}$.

Tipometría de la hoja: longitud máxima: $206 \mathrm{~mm}$; anchura máxima: $40 \mathrm{~mm}$; grosor máximo: 6,1 mm; peso: $177 \mathrm{~g}$.

Empuñadura y fragmento de hoja de espada pistiliforme. La guarda de la empuñadura es en forma de «V». El huso, ovalado, cuenta con una única perforación para roblón, mientras que el pomo está rematado por dos apéndices. La guarda presentaba originariamente cuatro orificios repartidos dos a dos. En la actualidad, en un caso, están unificados a modo de calado, mientras que en el otro, conserva uno de los roblones del empalme. La arista de la unión de la lengüeta con la hoja está decorada con finas muescas, insinuando el ricassos. También hay algunas muescas en el borde de la guarda, posiblemente relacionadas con un intento frustrado de decoración. 


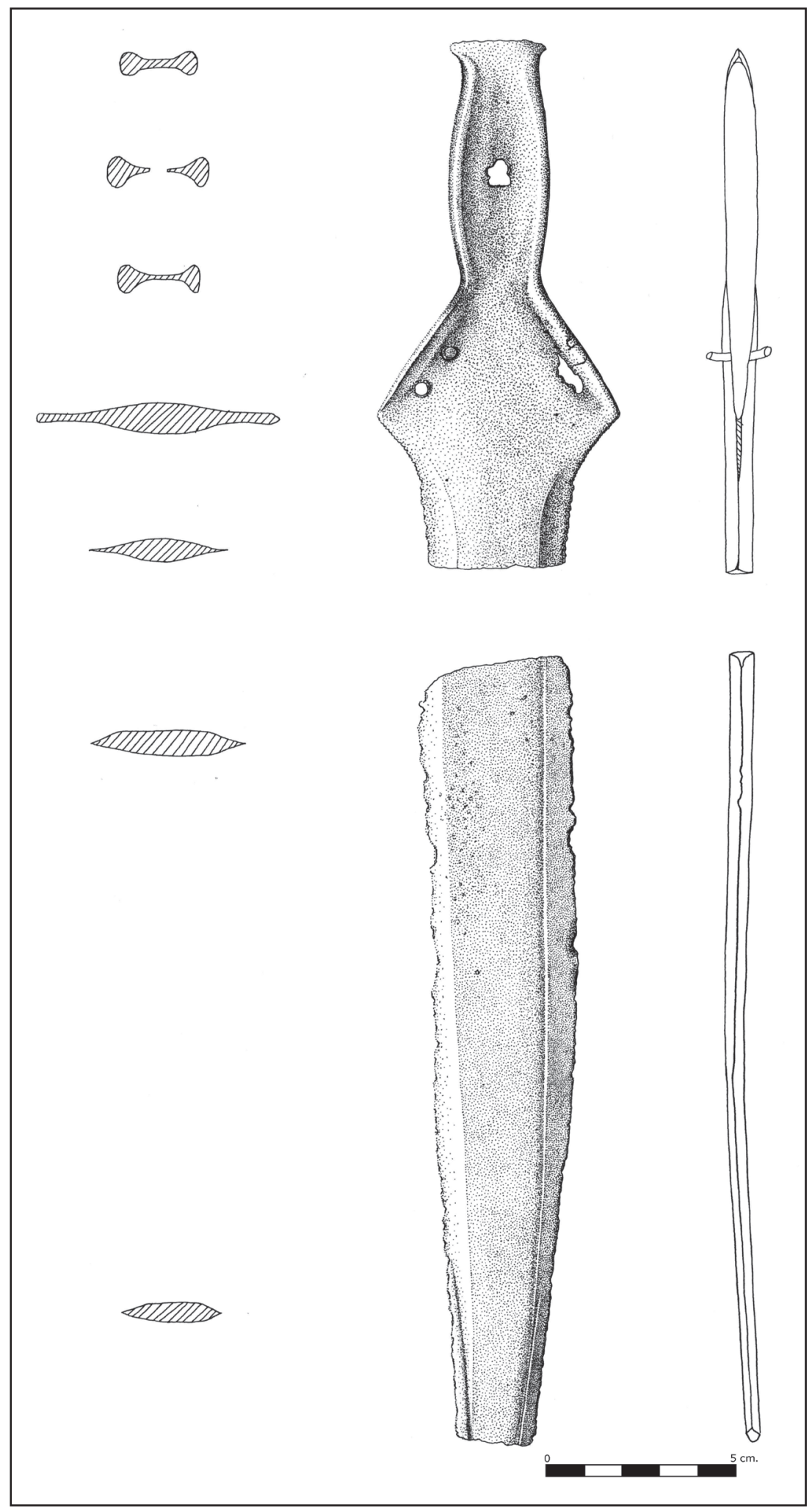

Figura 4. Empuñadura y hoja de espada n. ${ }^{0} 3 / 10$. 


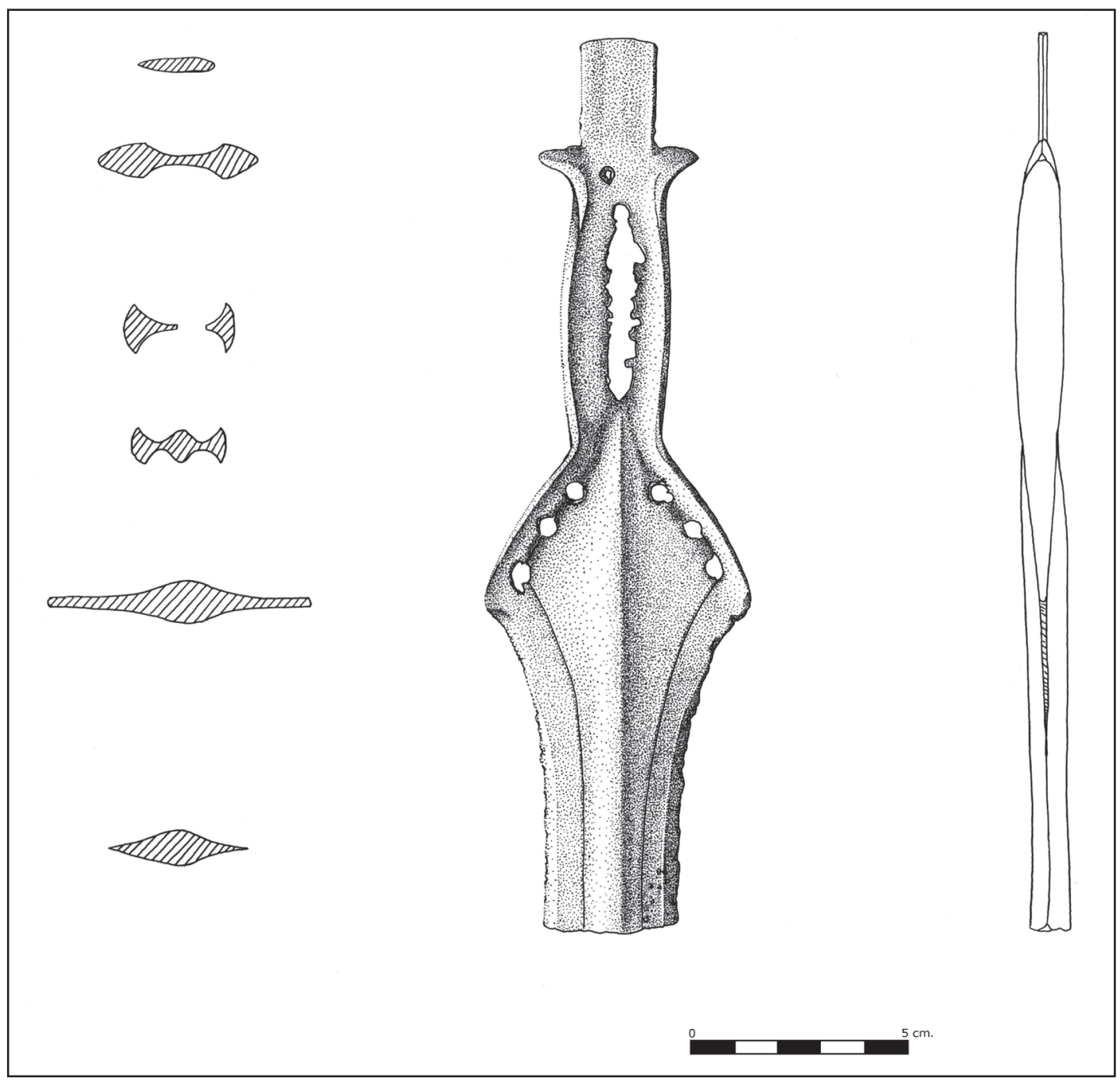

Figura 5. Empuñadura de espada n. ${ }^{\circ} 18$.

De la hoja se conservan $23 \mathrm{~cm}$ del arranque y un fragmento de poco más de $20 \mathrm{~cm}$, correspondiente al extremo distal del arma, aunque sin la punta. Se trata de una hoja muy plana, con ligerísima nervadura central, y carente de nervios decorativos.

\section{N. ${ }^{\circ}$ 18: Empuñadura (fig. 5)}

Tipometría: longitud máxima: $105 \mathrm{~mm}$; longitud de la hoja: $51 \mathrm{~mm}$; anchura máxima: 60 mm; grosor máximo: $8 \mathrm{~mm}$; peso: $198 \mathrm{~g}$.

Empuñadura con guarda en forma de «U» cerrada. El huso es ovalado, con una sucesión de perforaciones para los roblones que le proporcionan un aspecto calado debido a su rotura. La empuñadura se prolonga a partir de los apéndices del pomo en una lengüetilla de $26 \mathrm{~mm}$ de longitud, presentando en el punto de intersección una pequeña perforación, descentrada con respecto al eje de la pieza, para la sujeción de un roblón. La guarda presenta otras seis perforaciones para roblones, tres a tres. 

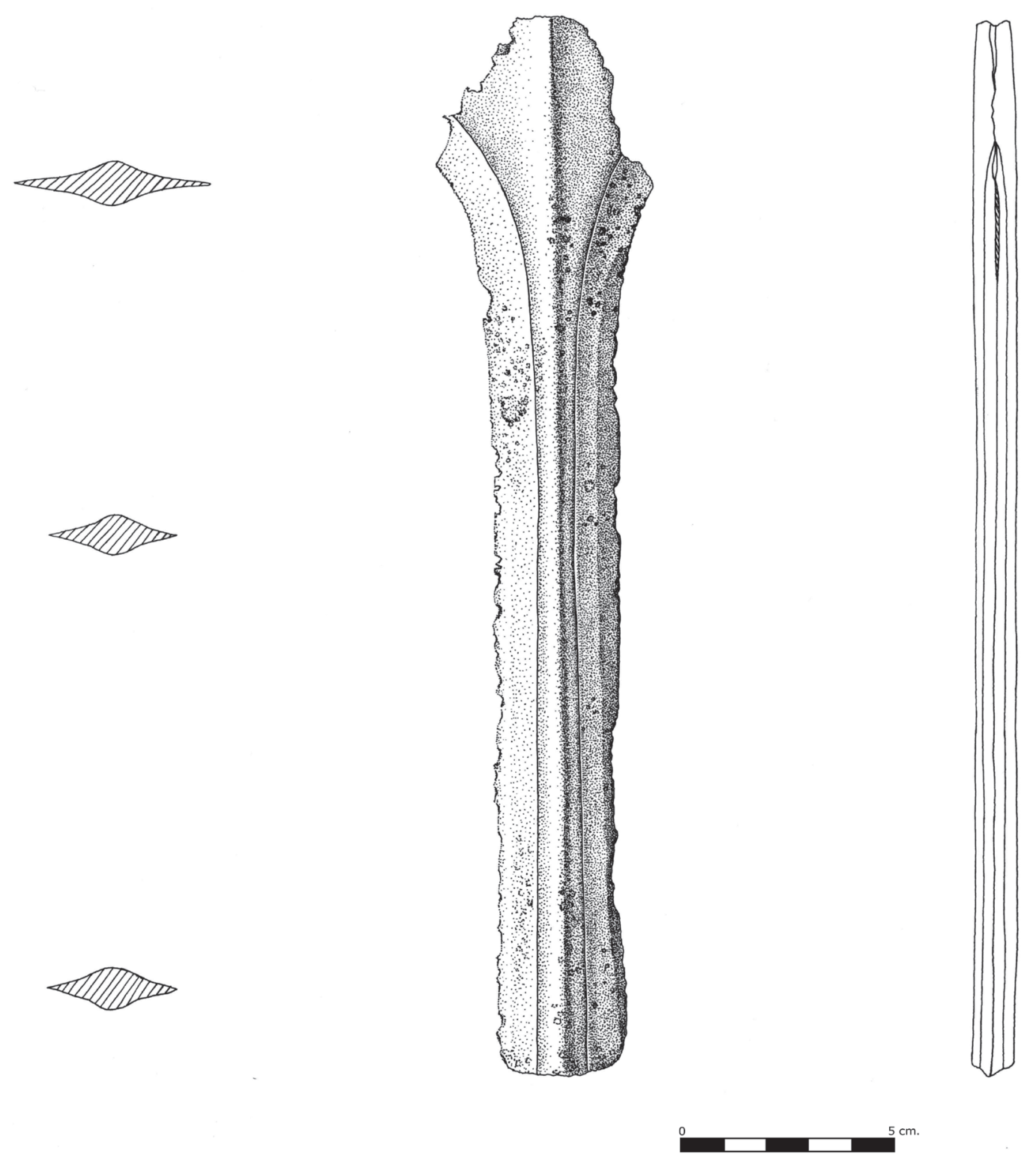

Figura 6. Hoja de espada n. ${ }^{\circ} 4$.

La hoja, de sección romboidal roma, cuenta con nervio central bien resaltado, flanqueado a cada lado por una incisión que se prolonga hasta las perforaciones de la guarda. La arista de la unión de la lengüeta con la hoja, donde se aprecia un ligerísimo ricassos, está decorada con finas muescas.

N. ${ }^{\circ}$ 4: Hoja (fig. 6)

Tipometría: longitud máxima: $245 \mathrm{~mm}$; anchura máxima: $46 \mathrm{~mm}$; grosor máximo: $10 \mathrm{~mm}$; peso: $274 \mathrm{~g}$. 
Fragmento proximal de hoja de espada pistiliforme, que conserva parte de la zona central de la guarda. La sección de la hoja es marcadamente romboidal, con nervio flanqueado por una incisión a cada lado.

\section{N. ${ }^{\circ}$ 5: Hoja (fig. 7)}

Tipometría: longitud máxima: $342 \mathrm{~mm}$; anchura máxima: $40 \mathrm{~mm}$; grosor máximo: 9,2 $\mathrm{mm}$; peso: $323 \mathrm{~g}$.

Fragmento proximal de hoja de espada pistiliforme. Conserva parte de la zona central de la guarda. La hoja, con acusado estrechamiento en el arranque, es de sección romboidal, y el nervio está flanqueado por una incisión a cada lado.

N. ${ }^{\circ}$ 6: Hoja (fig. 8)

Tipometría: longitud máxima: $509 \mathrm{~mm}$; anchura máxima: $48 \mathrm{~mm}$; grosor máximo: 9,9 $\mathrm{mm}$; peso: $548 \mathrm{~g}$.

Hoja de espada pistiliforme prácticamente completa. Conserva parte de la zona central de la guarda, aunque carece de punta. La hoja, con marcado estrechamiento en su primer tercio, es de sección romboidal. El nervio está flanqueado por una incisión a cada lado.

N. ${ }^{\circ}$ 7: Hoja (fig. 9)

Tipometría: longitud máxima: $521 \mathrm{~mm}$; anchura máxima: $41 \mathrm{~mm}$; grosor máximo: 9,8 $\mathrm{mm}$; peso: $573 \mathrm{~g}$.

Hoja de espada pistiliforme prácticamente completa. Conserva el arranque a partir de la guarda, aunque carece de punta. La hoja, con marcado estrechamiento en el arranque, es de sección romboidal. El nervio está flanqueado por una incisión a cada lado.

\section{N. ${ }^{\circ}$ 8: Hoja (fig. 10)}

Tipometría: longitud máxima: $308 \mathrm{~mm}$; anchura máxima: $37 \mathrm{~mm}$; grosor máximo: 8,8 mm; peso: $293 \mathrm{~g}$.

Fragmento distal de hoja de espada pistiliforme, que carece de punta. La sección es romboidal, y el nervio está flanqueado a cada lado por una incisión.

\section{N. ${ }^{\circ}$ 9: Hoja (fig. 11)}

Tipometría: longitud máxima: $276 \mathrm{~mm}$; anchura máxima: $33 \mathrm{~mm}$; grosor máximo: 8,9 mm; peso: $298 \mathrm{~g}$.

Fragmento distal de hoja de espada pistiliforme, que carece de punta. La sección es marcadamente romboidal, y el nervio está flanqueado a cada lado por una incisión.

\subsection{ANÁLISIS TIPOLÓGICO}

A finales del siglo XII la espada típica de la cultura de Campos de Urnas centroeuropea es la tipo Hemigkofen, de puño tripartito y hoja pistiliforme, caracterizada por el ensanchamiento del tercio inferior de la hoja. Estas espadas derivan de los modelos de Treviblice, características del periodo III de los Urnenfelder (Ha A 2), a partir de la fusión de las espadas tipo Unterhaching (Ha A 1) y Reutligen (Bz D/Ha A 1). El conjunto de las primeras espadas pistiliformes 


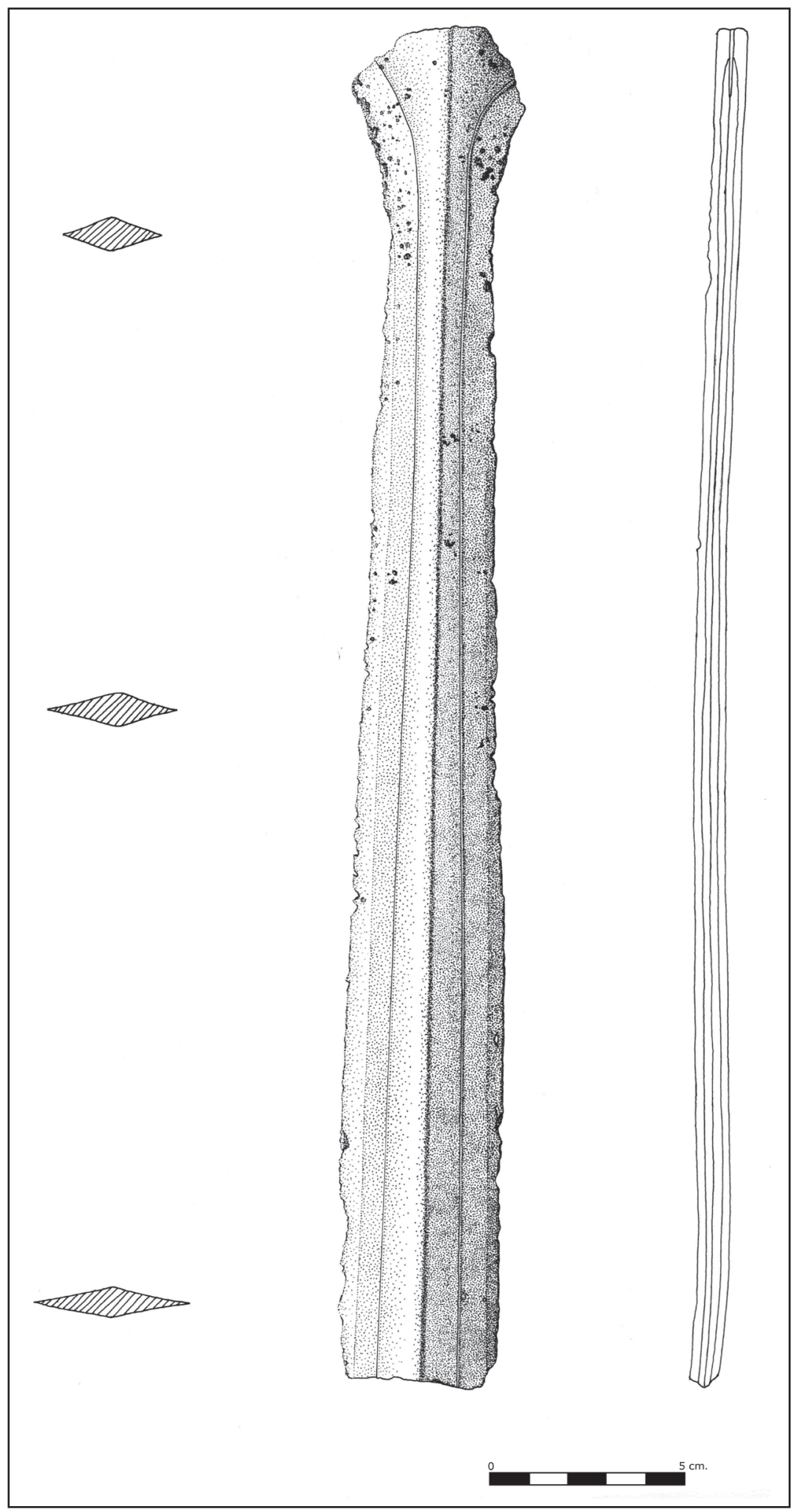

Figura 7. Hoja de espada n. ${ }^{\circ} 5$. 


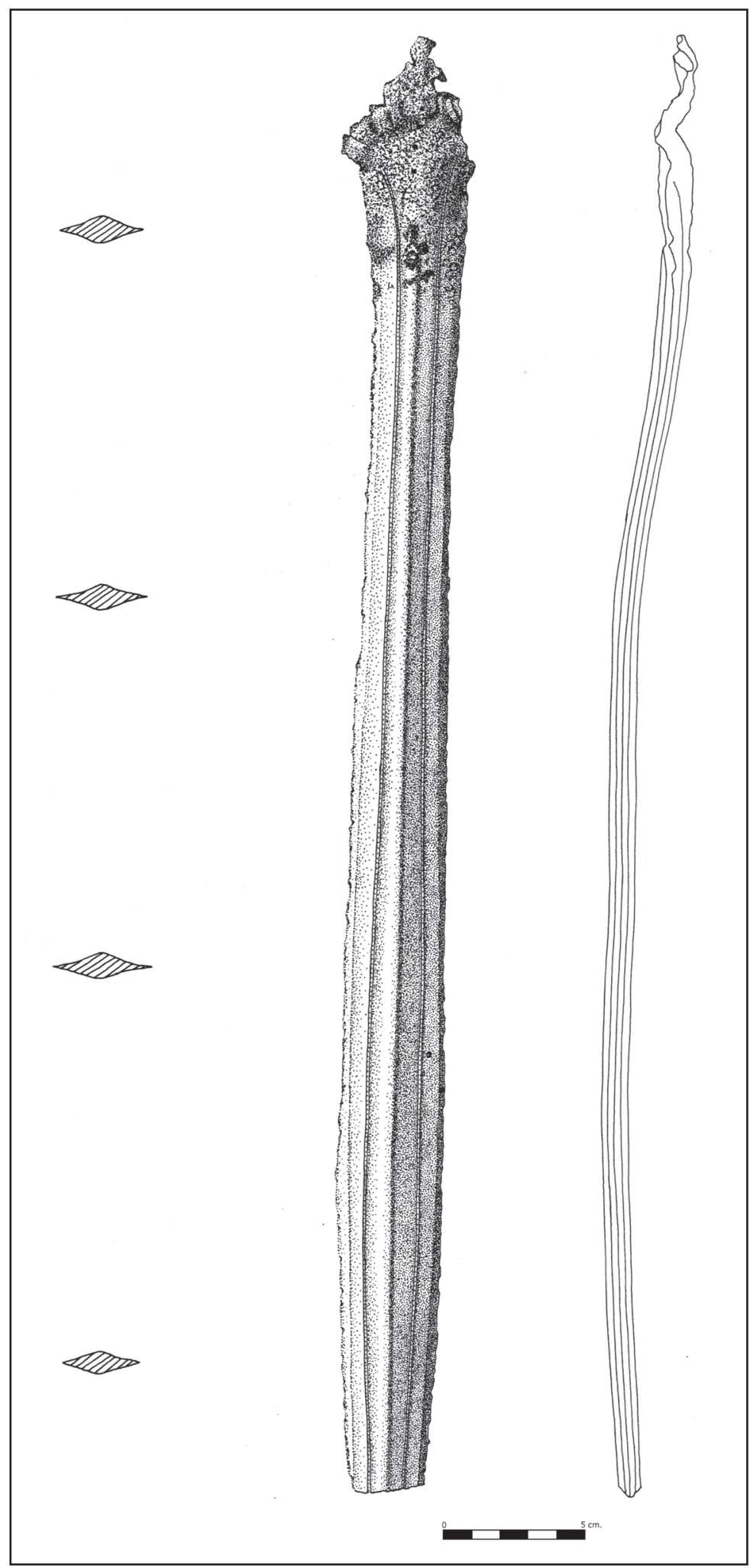

Figura 8. Hoja de espada . $^{\circ} 6$. 


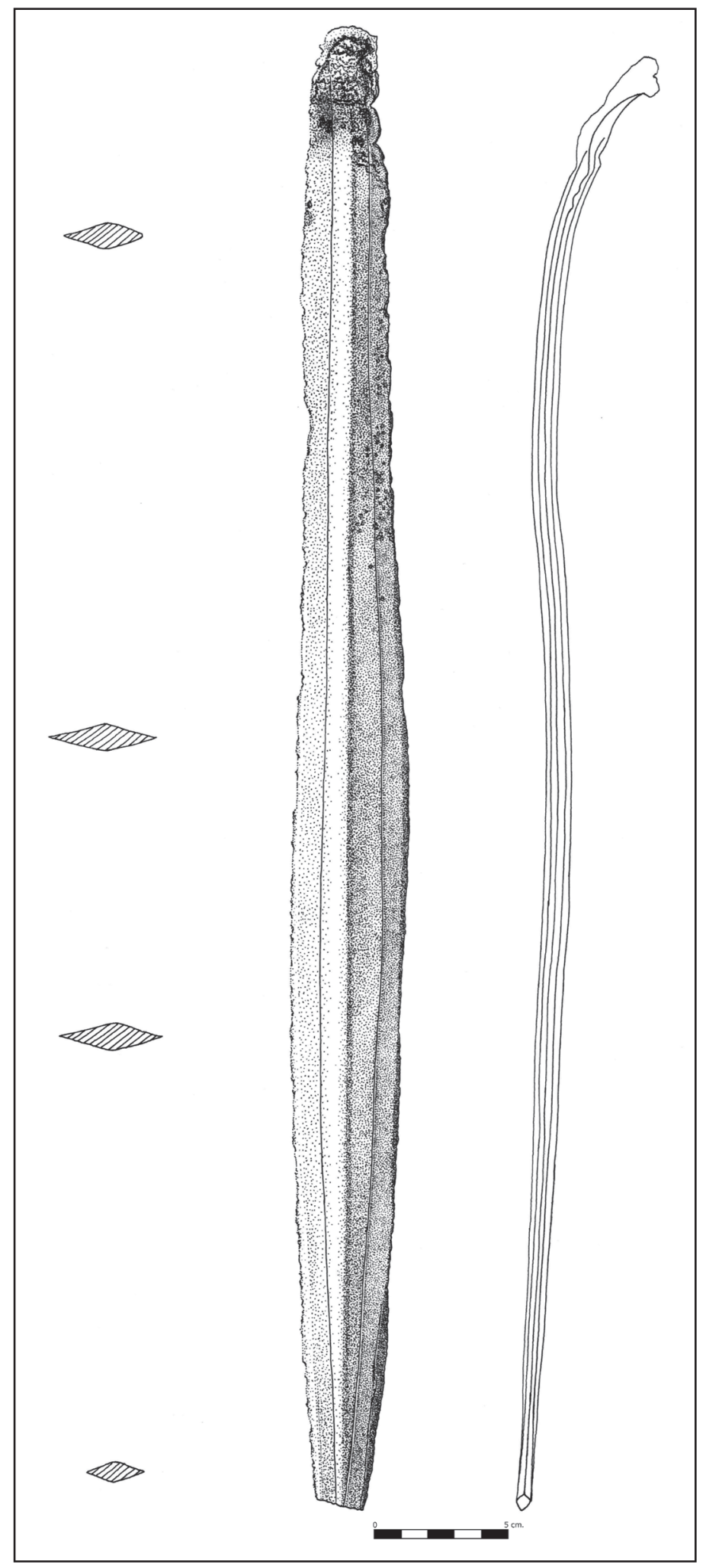

Figura 9. Hoja de espada n. ${ }^{\circ} 7$. 


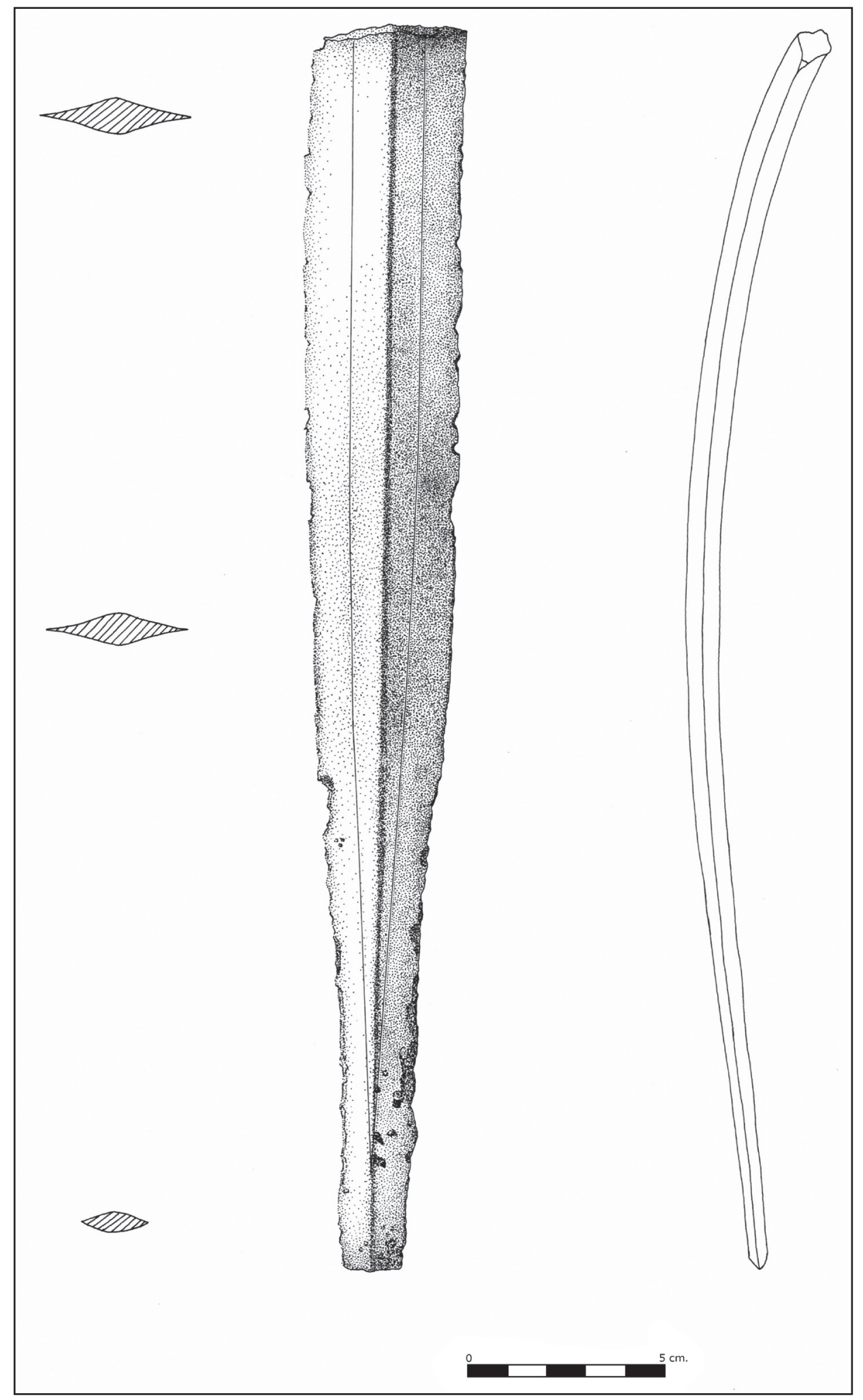

Figura 10. Hoja de espada n. ${ }^{\circ} 8$. 


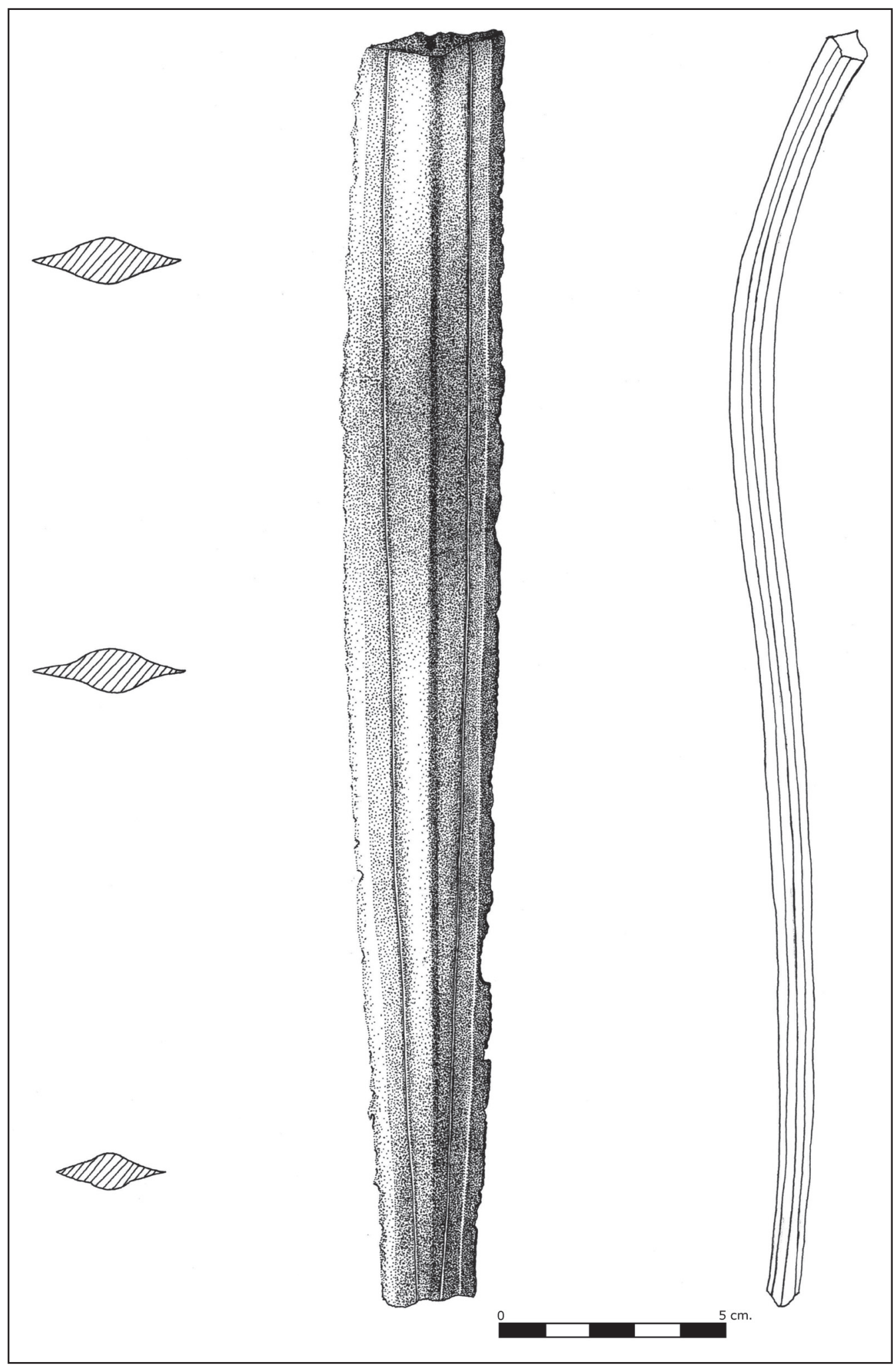

Figura 11. Hoja de espada n. ${ }^{\circ} 9$. 
se completa con el tipo Erbenheim, de controvertido origen centroeuropeo, documentado en contextos funerarios del Ha A.

La penetración de ambos tipos en las costas atlánticas coincide con el inicio del Bronce Final II (BFII) en la Península Ibérica, el final del periodo Penard en el sureste de Inglaterra, y el comienzo de la fase Saint-Denis-de Pile en la Gironda. Es comúnmente aceptada la idea de que, a partir de la importación de algunas piezas, comienza la fabricación de espadas de hoja pistiliforme inspiradas en estos modelos de la mano de artesanos locales, convirtiéndose en fósil guía de la etapa central del Bronce Final Atlántico.

En la Península Ibérica las características estilísticas de la mayoría de espadas pistiliformes, en torno a unos veinticinco ejemplares, que vendrán a sustituir a los característicos estoques del Bronce Final I (BFI), las diferencia de los modelos documentados en el resto de la Europa atlántica. Desde el punto de vista formal, como el resto de las espadas pistiliformes, se caracterizan por presentar un ensanchamiento de la hoja en el tercio inferior; sin embargo, por lo general, cuentan con una cierta diversidad formal, con variaciones más o menos próximas a los prototipos centroeuropeos de Hemigkofen o a las espadas de lengua de carpa peninsulares más precoces denominadas «tipo Huelva», el nuevo modelo de espada de puño tripartito, con la guarda en «V», filos paralelos y marcado estrechamiento en la punta, que sustituirá a las espadas pistiliformes como fósil guía del Bronce Final III (BFIII).

Entre las espadas pistiliformes peninsulares cabe citar los ejemplares leoneses del Museo de San Marcos, La Cabrera y Veguellina de Órbigo; junto con las de Segovia, Zaragoza, Alhama de Aragón (Zaragoza), Solacueva de Lacozmonte (Álava), Sobrefoz (Ponga, Asturias), San Juan del Río (Lugo), Evora (Portugal) y Vado de Mengíbar (Jaén); todas ellas, menos las dos últimas, procedentes de la Meseta Norte o de la zona septentrional del Valle del Ebro.

Frente a las piezas formalmente pistiliformes, existen otras que responden a modelos intermedios entre éstas y las de lengua de carpa, que presentan guarda en «V» $\mathrm{y} / \mathrm{o}$ hoja de bordes más o menos paralelos. A estos modelos pertenecen las espadas del Río Esla (Museo de Barcelona), Villaverde de Chiquita (León), Valga (Pontevedra), las portuguesas de Obidos y Alentejo, y algunas de las procedentes de la Ría de Huelva; además de los puñales de Paredes de Nava (Palencia) y de Elbas (Portugal).

En el depósito de Grañón han sido recuperados once fragmentos de espadas pistiliformes: cuatro empuñaduras o lengüetas y siete fragmentos de hojas, dos de ellas, las n. ${ }^{\circ} 6$ y 7 , prácticamente completas. Los fragmentos de hoja son marcadamente pistiliformes, especialmente las n. ${ }^{\circ}$ 4, 5, 6 y 7, lo que les confiere una apariencia muy estilizada, acorde con su longitud. Aunque no ha sido recuperada ninguna espada completa, la longitud original de las piezas se estima entre 60 y $70 \mathrm{~cm}$.

El análisis comparativo formal con respecto al resto de las espadas pistiliformes peninsulares sirve para descartar su parentesco, que no va más allá de pertenecer al amplio grupo de las espadas pistiliformes del Bronce Atlántico, ya que el depósito de Grañón no fue fundido por artesanos peninsulares; aunque en el caso de las empuñaduras n.$^{\circ} 18.1$ y 18.2 la guarda en «U» cerrada las aproxima a los ejemplares de Sobrefoz y Museo de León; y la forma de la guarda y la estrecha unión de ésta con el uso tenga una cierta similitud con la espada de Solacueva de Lakozmonte (Jócano, Álava); o las hojas más marcadamente pistiliformes, como las n. ${ }^{\circ}$ 4, 5, 6 y 7, se aproximen a las de Veguellina de Órbigo, Vado de Mengibar y Sobrefoz.

La posible existencia en la Península de espadas importadas del Bronce Final procedentes de otras regiones europeas ha sido discutida a lo largo de las últimas décadas (Delibes et alii, 1999: 65), aunque por lo general cuenta con pocos argumentos de sustentación. El ejemplo más clásico quizá sea la espada procedente de Zaragoza, considerada por algunos autores como una genuina Hemigkofen (Barril, Delibes y Ruiz, 1982: 375), que, sin embargo, cuenta con importantes diferencias formales que la separan de tal tipología. 
Dentro del depósito de Grañón, la pieza más novedosa a nivel peninsular es la empuñadura n. $^{\circ}$ 18, de tipo Erbenheim. Lo más característico de este tipo de espada pistiliforme es el apéndice axial en forma de lengüetilla que se prolonga en el extremo proximal del pomo, flanqueado a su vez por dos apéndices laterales. Las espadas tipo Erbenheim o bien carecen de ricassos, o bien aparece levemente insinuado en forma de ligera escotadura. La sujeción al pomo se realiza mediante roblones, contando para ello con perforaciones, de 4 a 5 en el uso, y de 6 a 8 en la guarda, mientras que la longitud de la hoja, de entre 66 y $72 \mathrm{~cm}$, similar a la estimada para las armas de Grañón, las separa de los modelos tipo Hemigkofen, más cortas y menos estilizadas (Gaucher y Mohen, 1972: 521-522).

Con respecto al origen estilizado de la hoja de este tipo de espada, Cowen (1951) lo encuentra en espadas de la Europa del Este, como las de Budapest, donde conviven empuñaduras similares con hojas estilizadas y de bordes paralelos. Sin embargo, estas armas parecen datadas en el Ha A 2, por lo que difícilmente pueden haber influido en el desarrollo de las tipo Erbenheim. Para Burgués y Colquhoun (1988) hay dos posibles respuestas: la derivación natural de la hoja hacia el refinamiento y la estilización, o la influencia Vollgriffchwerter del Ha A 1, donde algunas espadas cuentan con proporciones y longitud similares a las Erbenheim.

El origen de la empuñadura también es problemático, ya que hay otros dos tipos de espadas con una empuñadura similar: la tipo Letten y la tipo Allerona; sin embargo, ni por distribución ni por cronología parece posible que puedan haber influido en las tipo Erbenheim (Burgués y Colquhoun, 1988: 30). La datación también resulta controvertida, debido a la dificultad de correlacionar las secuencias del centro y el norte de Europa, aunque mayoritariamente parece aceptado que surgen en el Ha A 2.

La mayoría de los ejemplares recuperados están concentrados en la zona central y baja del Rin, dispersándose hacia el este y el sur a Alemania y Suiza, y hacia el oeste hacia Francia e Inglaterra. Esta distribución es geográficamente similar a la del tipo Hemigkofen, aunque en el último caso se observa una mayor concentración de ejemplares en Suiza y sur de Alemania (ibíd.: 31). La empuñadura Erbenheim de Grañón viene a enriquecer y ampliar el mapa de distribución de este tipo de espada, inédito hasta la fecha en la Península Ibérica. .

Con respecto al lugar de procedencia de la empuñadura riojana, cabe señalar que cuenta con las características generales de las producciones Erbenheim centroeuropeas, con las que comparte, entre otros aspectos, la larga empuñadura, el número de roblones y la elegancia de la hoja, pero presenta ciertas particularidades que la asimilan a determinados ejemplares británicos de manufactura local, ya esgrimidos por Schauer en 1971 y posteriormente revisados por Burgués y Colquhoun. Ambos autores describen la empuñadura Erbenheim de tipo británico a partir de dos espadas recuperadas en Londres: la espada Battersea (ibíd.: n. ${ }^{\circ} 83$ ), dragada en el río Támesis, y la espada Stratford (ibíd.: n. ${ }^{\circ} 84$ ), procedente del río Lea, ambas datadas a finales del periodo Penard (1200-1000 a.C.).

En los dos ejemplares los aspectos formales que las alejan de la clásica Erbenheim son la mayor delgadez y estilización del huso, y la forma convexa de los hombros de la guarda, en forma de «U» cerrada. El origen de la forma convexa y redondeada de los hombros no es fácil de explicar, aunque está constatado en algunas espadas del norte de Europa, como las procedentes de yacimiento danés de Neble, con empuñaduras similares a la espada Battersea, o en ciertas espadas de Budapest (ibíd.: 30), aunque el paralelo más próximo son algunas espadas procedentes del noroeste de Francia, entre ellas una Erbenheim recuperada en el Sena a su paso por París (Gaucher y Mohen, 1972: 521-522).

La empuñadura de Grañón cuenta con importantes similitudes con todos estos ejemplares, pero con la espada Stratford tiene un parecido que raya en la identidad, incluidas las finas líneas incisas que decoran la zona del ricassos. La equivalencia no se circunscribe únicamente 
a aspectos estilísticos, ya que las dimensiones de las dos armas son también análogas, por lo que no resulta aventurado considerar el ejemplar riojano un objeto importado de las islas británicas, teniendo en cuenta la manufactura local de la espada Stratford.

Tal afirmación, en principio, asimila el conjunto de las piezas del depósito al mismo origen, por lo que es necesario proceder al análisis del resto de las empuñaduras y hojas de espada para poder avanzar en este sentido. Con respecto a las hojas, aunque no se han recuperado sus empuñaduras, hay un aspecto formal común que las caracteriza: su ya mencionada longitud y la estilización de su forma pistiliforme, dos características fácilmente asimilables a los tipos Erbenheim o Clewer; este último, considerado en Gran Bretaña el segundo momento de desarrollo de las espadas importadas después de las tipo Erbenheim, cuenta con una evolución paralela en Francia. Con respecto a la distribución, ya se ha comentado que las espadas Erbenheim británicas se concentran prácticamente en el sureste de la isla, en concreto en el Támesis y sus afluentes. Por su parte, las espadas tipo Clewer cuentan en Inglaterra con una distribución similar a las Erbenheim, a la par que existen ejemplares en el norte de Irlanda y en Francia, en este caso distribuidas por el oeste, desde Normandía hasta la Gironda (Burgués y Colquhoun, 1988: 33).

Desde el punto de vista formal el tipo Clewer es en esencia similar al tipo Erbenheim, siendo su mayor diferencia el tamaño de la empuñadura, ligeramente más pequeña. De hecho, algunos de los ejemplares tipo Clewer parecen haber contado en el extremo del pomo con la característica lengüetilla de las empuñaduras Erbenheim, que habrían perdido por rotura (ibíd.: 31). Esta misma circunstancia puede haber pasado en las empuñaduras n. ${ }^{\circ} 1$ y 2 de Grañón. En el primer caso, el extremo del pomo está rematado con dos apéndices que en principio la aproximan a la característica «cola de pez» de los prototipos Hemigkofen, aunque está claramente incompleto debido a su rotura. Algo similar puede haber sucedido en la empuñadura n. ${ }^{\circ}$ 2, donde el terminal, aunque afinado, tiene una arista excesivamente rugosa, que invita a pensar que pudo tener el mencionado apéndice. En ambos casos, la forma convexa de los hombros las acerca a las producciones británicas Erbenheim y Clewer, en especial a la espada Battersea (ibíd.: n. ${ }^{\circ} 83$ ), considerada el ejemplo más precoz de la empuñadura Erbenheim británica, aunque la forma del uso dista de ésta.

El ejemplar $n .^{\circ} 3$, al que se le atribuye el fragmento de hoja $n .^{\circ} 10$, presenta marcadas diferencias con respecto al resto de empuñaduras y hojas. El reducido tamaño del pomo la aproxima al tipo Clewer, pero la forma de la guarda en «V» la acerca más a las espadas Erbenheim continentales, tales como la Wollmesheim del Palatinado renano (Almagro, 1940: 103). Sin embargo, también la espada Brentford de tipología Erbenheim (ibíd.: n. ${ }^{\circ} 85$ ), dragada en el Támesis a su paso por Middlesex, cuenta en su fisonomía con características que la aproximan al ejemplar alemán, aunque no parece haber dudas sobre su manufactura local. Otros aspectos que diferencian la empuñadura $n .^{\circ} 3$ con respecto al resto de las empuñaduras y hojas que integran el depósito son: el número de perforaciones para roblones del uso, uno solamente; la sección de la hoja, marcadamente plana al carecer de nervadura central; y la ausencia de incisiones decorativas paralelas a los filos.

Las empuñaduras n. ${ }^{\circ} 1,2$ y 3 cuentan con otra característica que las relaciona nuevamente con la espada Brentford, a pesar de que la n..$^{\circ} 3$ no parece haber tenido la lengüetilla en el remate del pomo, y es el número de perforaciones para los roblones de la guarda, cuatro en cada caso, aunque en la n. ${ }^{\circ} 3$, puede haber tenido únicamente tres, teniendo en cuenta las proporciones de su distribución. En este sentido, tanto las empuñaduras riojanas como la espada Brentford están más próximas a las espadas tipo Letten continentales, en las que este número de roblones en la guarda es habitual (Gaucher y Mohen, 1972: 521-522), o a ciertos ejemplares británicos tipo Hemigkofen. 
Otro aspecto importante a tener en cuenta es que las cuatro empuñaduras de Grañón cuentan con decoraciones a base de líneas incisas paralelas en la zona de unión de la empuñadura con la guarda, insinuando el ricassos, característico de muchas espadas británicas y francesas pistiliformes. En el caso de la empuñadura n. ${ }^{\circ} 2$, la ornamentación se extiende a los bordes de la lengüeta, de manera muy similar a las decoraciones de algunas espadas húngaras Griffzungenschwerter tipo C variantes 6 y 7, tipo D variante 1, y tipo E variante 1 (Kemenczei, 1988), pero aún más próxima a la decoración de la espada francesa Saint-Hilaire-la-Palud, de tipo Libourne-Condat (Gómez, 2007: 269), con cuyo uso guarda una evidente similitud, o a la espada recuperada en el Támesis en Chiswick (Burgués y Colquhoun, 1988: n. ${ }^{\circ} 100$ ) tipo Limehouse. Esta misma intencionalidad ornamental podrían tener las muescas visibles en el borde de la guarda de la empuñadura $n .^{\circ} 3$, interpretadas como un intento frustrado de decoración.

La variedad formal representada en las cuatro empuñaduras riojanas puede ser interpretada como disparidad cronológica; sin embargo, por lo general, los objetos componentes de un depósito suelen pertenecer a un mismo periodo. De hecho, algunos autores como K. Kristiansen, opinan que no es cierto que los depósitos contengan objetos de distintos periodos, y que las excepciones son reflejo de épocas de escasez de metales o el hallazgo casual de depósitos en la propia Edad del Bronce (Kristiansen, 2001: 128). En el caso que nos ocupa, parece demostrada la filiación inglesa de la empuñadura n. $^{\circ}$ 18, de tipo Erbenheim, lo que encuadra topográfica y cronológicamente el arma, y por extensión el resto de las piezas, a finales del periodo Penard, entre 1200 y 1000 a.C., en el tránsito al periodo Wilburton (tránsito entre el BFI y BFII). Sin embargo, tampoco podemos descartar que el depósito, en su largo recorrido a través de la Europa atlántica, se viese incrementado con objetos de diferentes procedencias antes de terminar su periplo en territorio riojano, lo que explicaría determinados aspectos decorativos y los diferentes influjos tipológicos que conviven, como hemos visto, en una misma pieza, más o menos próximos a los prototipos Hemigkofen, Erbenheim o Clewer, y que caracterizan a las diferentes producciones locales de espadas pistiliformes del ámbito atlántico.

\section{PUNTAS DE LANZA DE ENMANGUE TUBULAR}

\subsection{INVENTARIO}

N. ${ }^{\circ}$ 11: Punta de lanza de enmangue tubular (fig. 12)

Tipometría: longitud máxima: $225 \mathrm{~mm}$; anchura máxima: $53 \mathrm{~mm}$; grosor máximo: 23,7 $\mathrm{mm}$; peso: $155 \mathrm{~g}$.

Punta de lanza de enmangue tubular corto en el tramo exento $(26 \mathrm{~mm})$, pero de gran desarrollo longitudinal en la hoja. La bóveda del tubo es marcadamente apuntada, por lo que la sección del enmangue es romboidal. Los alerones son anchos y desarrollados en el extremo proximal, y muy afilados y estrechos en el distal. En la unión de la hoja y el enmangue, cuenta con dos perforaciones afrontadas para el pasador de sujeción. La matriz supera los dos tercios de la hoja.

\section{N. ${ }^{\circ}$ 12: Punta de lanza de enmangue tubular (fig.13)}

Tipometría: longitud máxima: $199 \mathrm{~mm}$; anchura máxima: $37 \mathrm{~mm}$; grosor máximo: $22 \mathrm{~mm}$; peso: $162 \mathrm{~g}$

Punta de lanza de enmangue tubular corto, de sección circular. E1 tramo exento mide 52 mm. Alerones redondeados y de poco desarrollo. En la unión de la hoja y el enmangue, cuenta con sendas perforaciones afrontadas para el pasador de sujeción. La matriz alcanza los dos tercios de la hoja. 


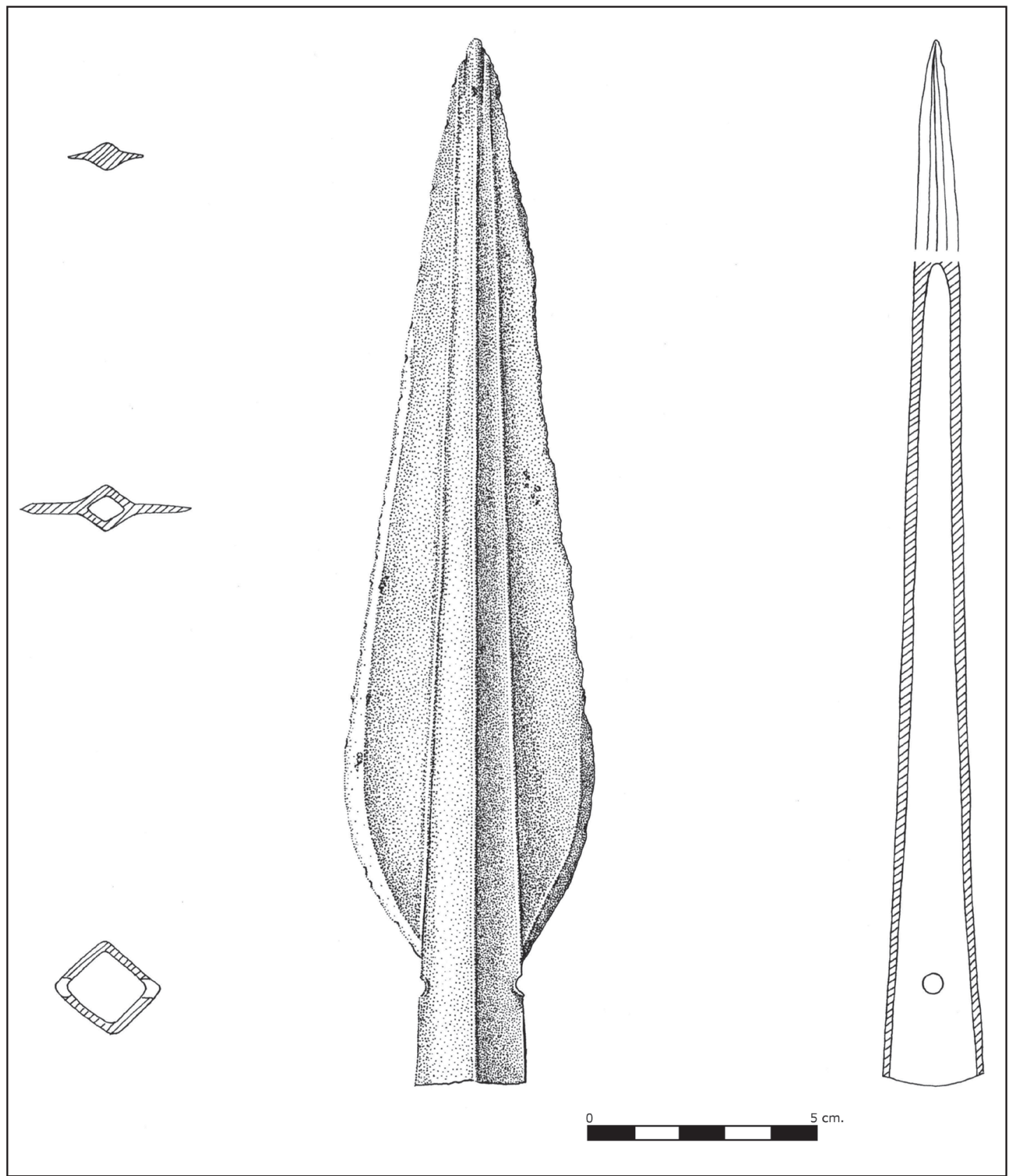

Figura 12. Punta de lanza de enmangue tubular n. ${ }^{\circ} 11$.

N. ${ }^{\circ}$ 13: Fragmento de punta de lanza de enmangue tubular (fig. 14)

Tipometría: longitud máxima: $154 \mathrm{~mm}$; anchura máxima: $37 \mathrm{~mm}$; grosor máximo: 20,4 $\mathrm{mm}$; peso: $98 \mathrm{~g}$.

Fragmento distal de punta de lanza de enmangue tubular. Conserva parte de los alerones, redondeados y de escaso desarrollo. El enmangue a lo largo de la hoja presenta pronunciada nervadura, con sección marcadamente oval. La matriz se prolonga hasta la mitad de la hoja. 

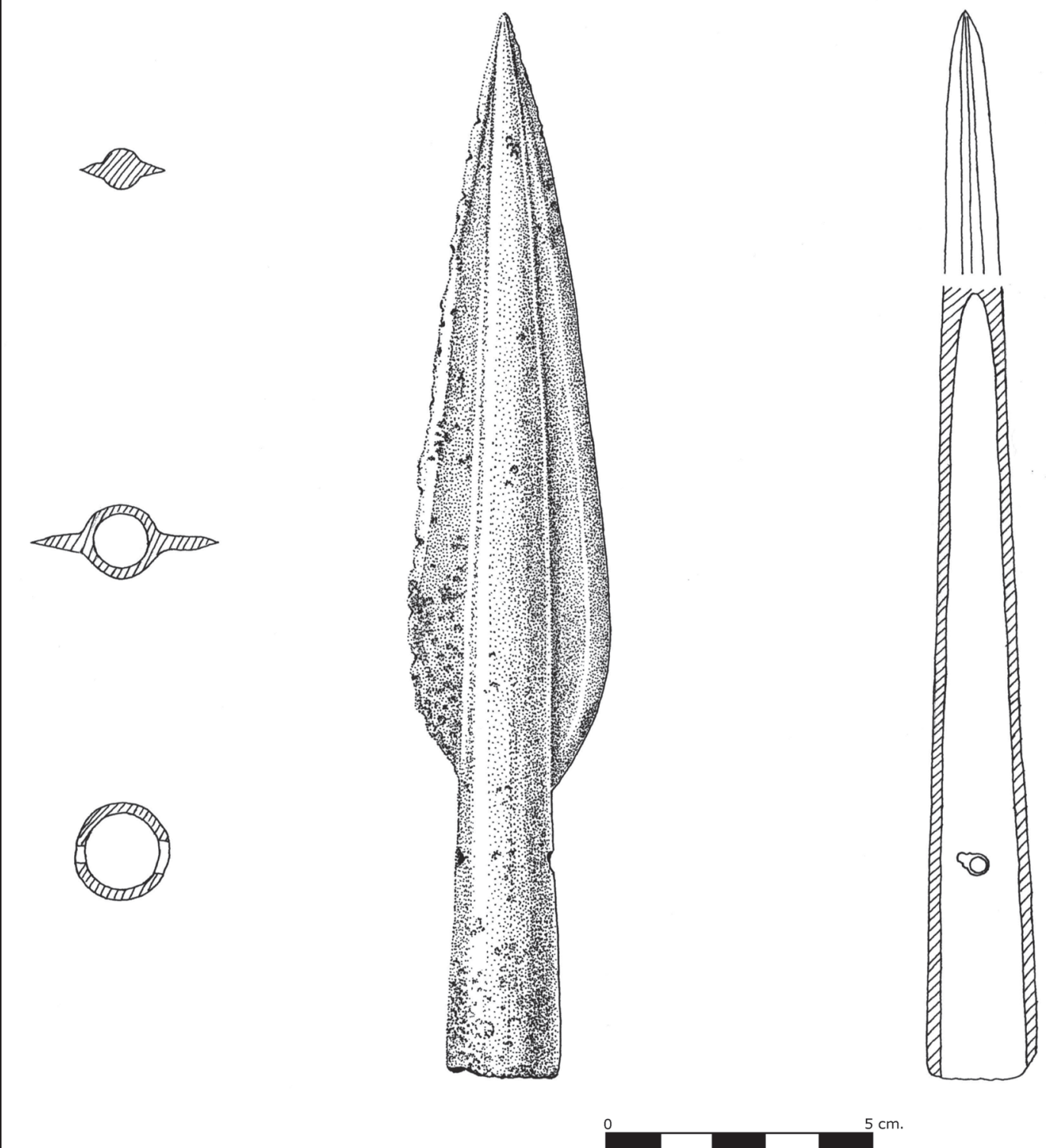

Figura 13. Punta de lanza de enmangue tubular n. ${ }^{\circ} 12$.

N. ${ }^{\circ}$ 14: Fragmento de punta de lanza de enmangue tubular (fig.15)

Tipometría: longitud máxima: $110 \mathrm{~mm}$; anchura máxima: $37 \mathrm{~mm}$; grosor máximo: 24,4 $\mathrm{mm}$; peso: $56 \mathrm{~g}$.

Fragmento proximal de punta de lanza de enmangue tubular corto en el tramo exento (33 $\mathrm{mm}$ ). Alerones de escaso desarrollo, aunque, teniendo en cuenta el deterioro de los bordes, en origen pudieron tener mayor anchura. El tubo es de sección circular, y en el enmangue está flanqueado por sendas perforaciones afrontadas para el pasador de sujeción. 


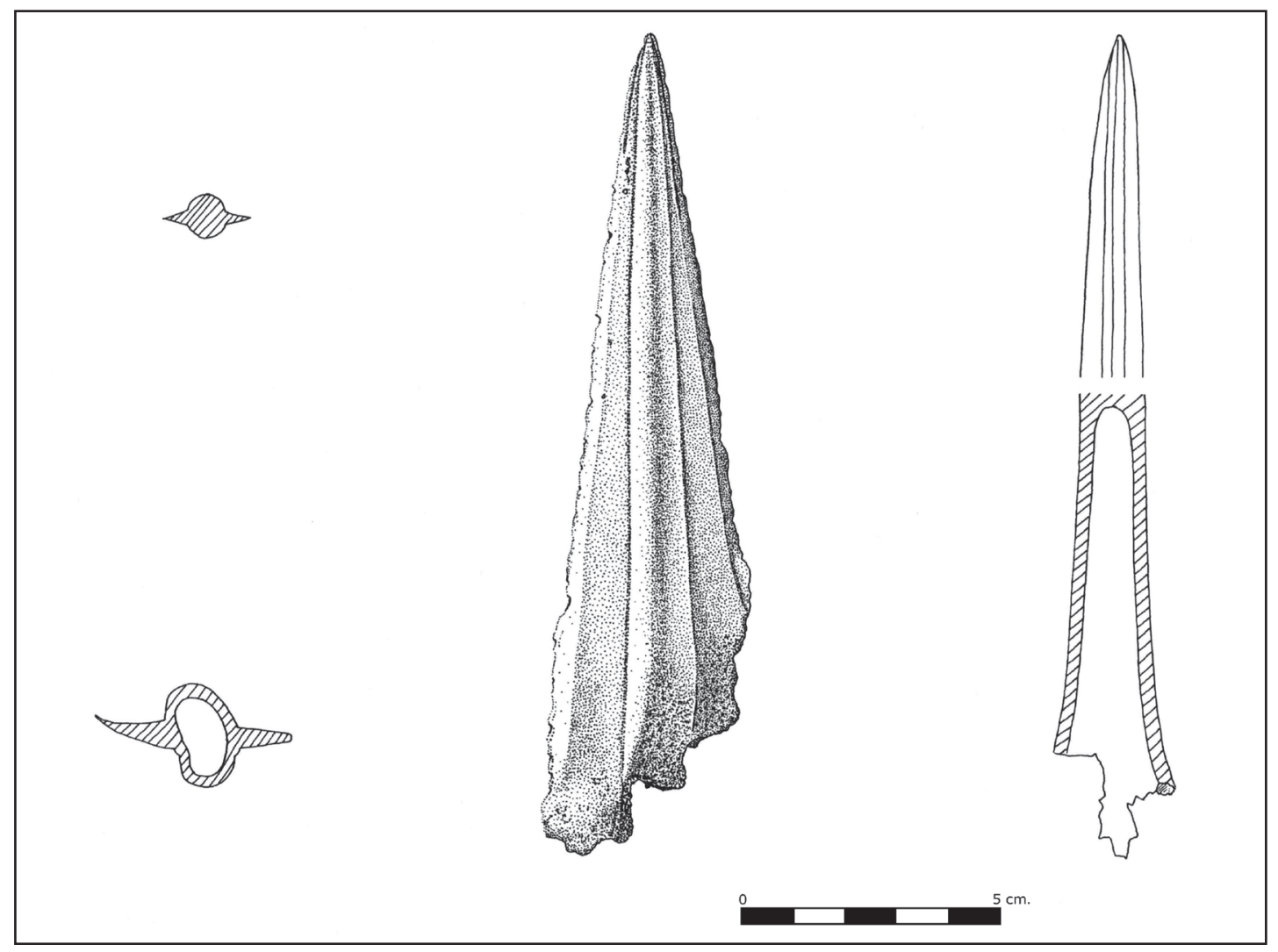

Figura 14. Fragmento de punta de lanza de enmangue tubular n. ${ }^{\circ} 13$.

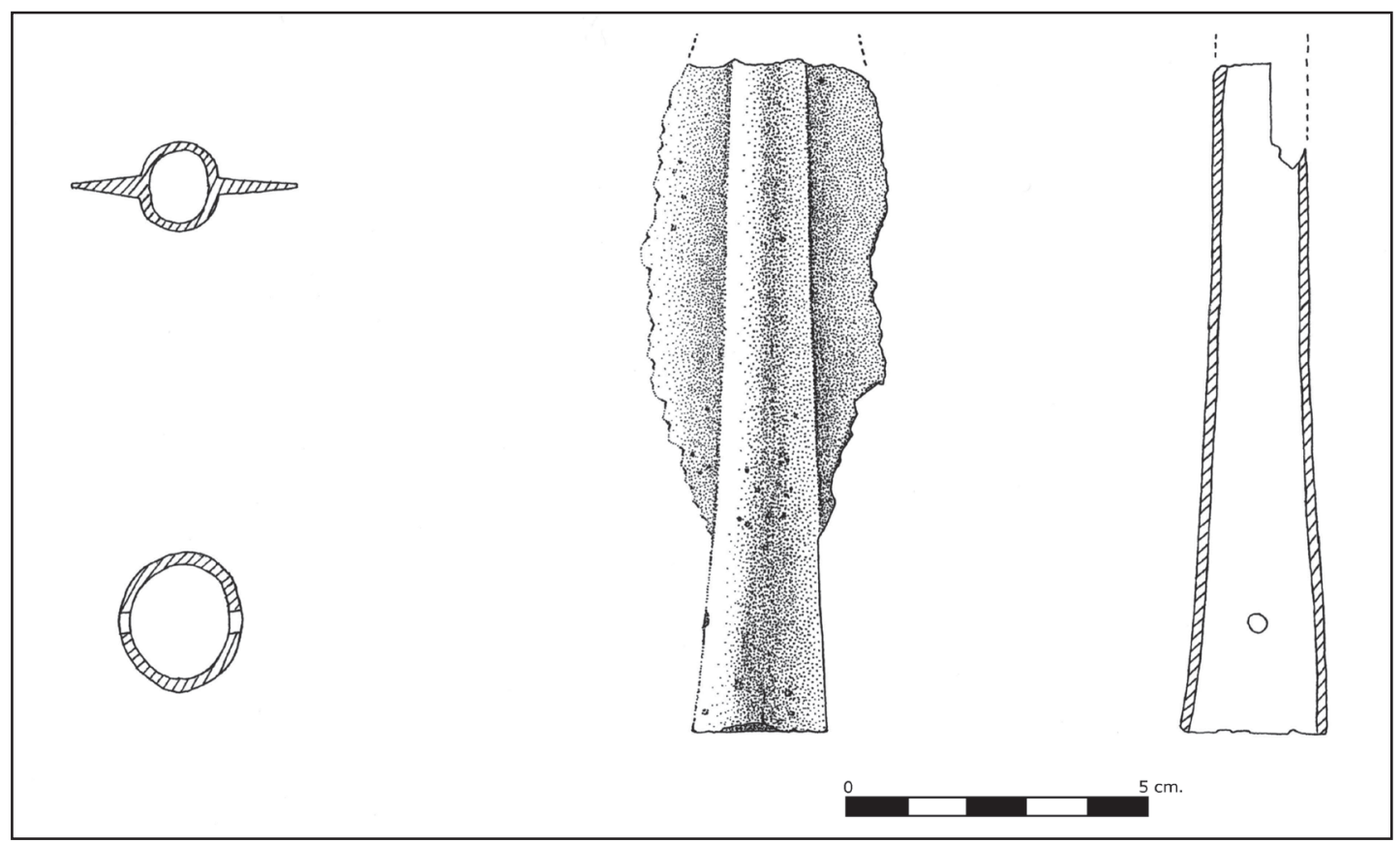

Figura 15. Fragmento de punta de lanza de enmangue tubular n. ${ }^{\circ} 14$. 


\subsection{ANÁLISIS TIPOLÓGICO}

Al abordar el análisis de las puntas de lanza tubular de la Edad del Bronce, que surgen en el centro y occidente de Europa hacia la decimocuarta centuria, aparecen los ya clásicos inconvenientes relacionados fundamentalmente con la prolongada perduración cultural del objeto, que abarca desde el Bronce Medio hasta la Edad del Hierro, así como con su escasa evolución formal a grandes rasgos, lo que dificulta la vinculación a un momento cronocultural concreto, sobre todo en los ejemplares descontextualizados o no asociados a otras piezas de cronología más clara.

En el caso que nos ocupa, esta problemática parece resuelta ya que las cuatro puntas de lanza procedentes de Grañón - dos ejemplares completos (n. ${ }^{\circ} 11$ y 12), un extremo proximal (n. $\left.{ }^{\circ} 13\right)$ y un extremo distal (n. $\left.{ }^{\circ} 14\right)$ - están asociadas a las empuñaduras y hojas descritas, contextualizadas en el tránsito entre el BFI y el BFII. Sin embargo, resulta significativo, como viene siendo frecuente en el estudio de piezas similares, la coincidencia en un mismo objeto de rasgos considerados arcaicos con otros evolucionados (Briard, 1965), que individualizan unas piezas con otras y determinan la variedad morfológica del conjunto, propia de la diversidad formal de este tipo de arma.

A rasgos generales, los ejemplares riojanos se ajustan a algunas características tipo de las puntas de lanza tubulares del BFII, como la longitud del tubo, corto en el tramo exento, representando un $11,1 \%$ de la longitud total de la punta de lanza $n .^{\circ} 11$, y un $27,6 \%$ de la n. ${ }^{\circ} 12$. Otra característica de las piezas de este periodo es el ensanchamiento de los alerones en el primer tercio, atribuible de manera más rotunda a la punta de lanza $n .^{\circ} 11$.

Por otro lado, las características formales arcaicas son también muy claras, como la profundidad de la matriz tubular, que en las piezas $n .^{\circ} 11$ y 12 supera las tres cuartas partes de su desarrollo, o el adelgazamiento progresivo del tubo hasta el contacto con los alerones, mucho más acusado en ejemplares evolucionados. También el desarrollo general de los alerones, de cierta anchura, es otro signo de antigüedad.

Por último, en el caso de la punta de lanza n. ${ }^{\circ}$ 11, la sección del tubo es romboidal, similar al ejemplar de mayor tamaño de las tres puntas de lanza procedentes del depósito de Castromocho (Palencia), característica también apreciable en una punta del depósito de Huelva (Almagro, 1940: 131), que M. Almagro interpreta como señal de antigüedad.

Por lo tanto, parece clara la confluencia de características formales antiguas con otras más evolucionadas, algo lógico dentro de la cronología en la que está encuadrado el depósito.

\section{REGATONES}

\subsection{INVENTARIO}

N. ${ }^{\circ}$ 15: Regatón (fig. 16)

Tipometría: longitud máxima: 209 mm; diámetro máximo: 20,7 mm; peso: 132 g.

Regatón liso, tubular, de punta roma y sección circular. Cuenta con sendas perforaciones afrontadas para el pasador de sujeción, a $42 \mathrm{~mm}$ del extremo del enmangue.

$N .^{\circ}$ 16: Regatón fragmentado (fig. 17)

Tipometría: longitud máxima: $218 \mathrm{~mm}$; diámetro máximo: $20 \mathrm{~mm}$; peso: $125 \mathrm{~g}$.

Regatón liso, tubular, de sección circular, al que falta la punta. Cuenta con sendas perforaciones afrontadas para el pasador de sujeción, a $70 \mathrm{~mm}$ del extremo del enmangue. 


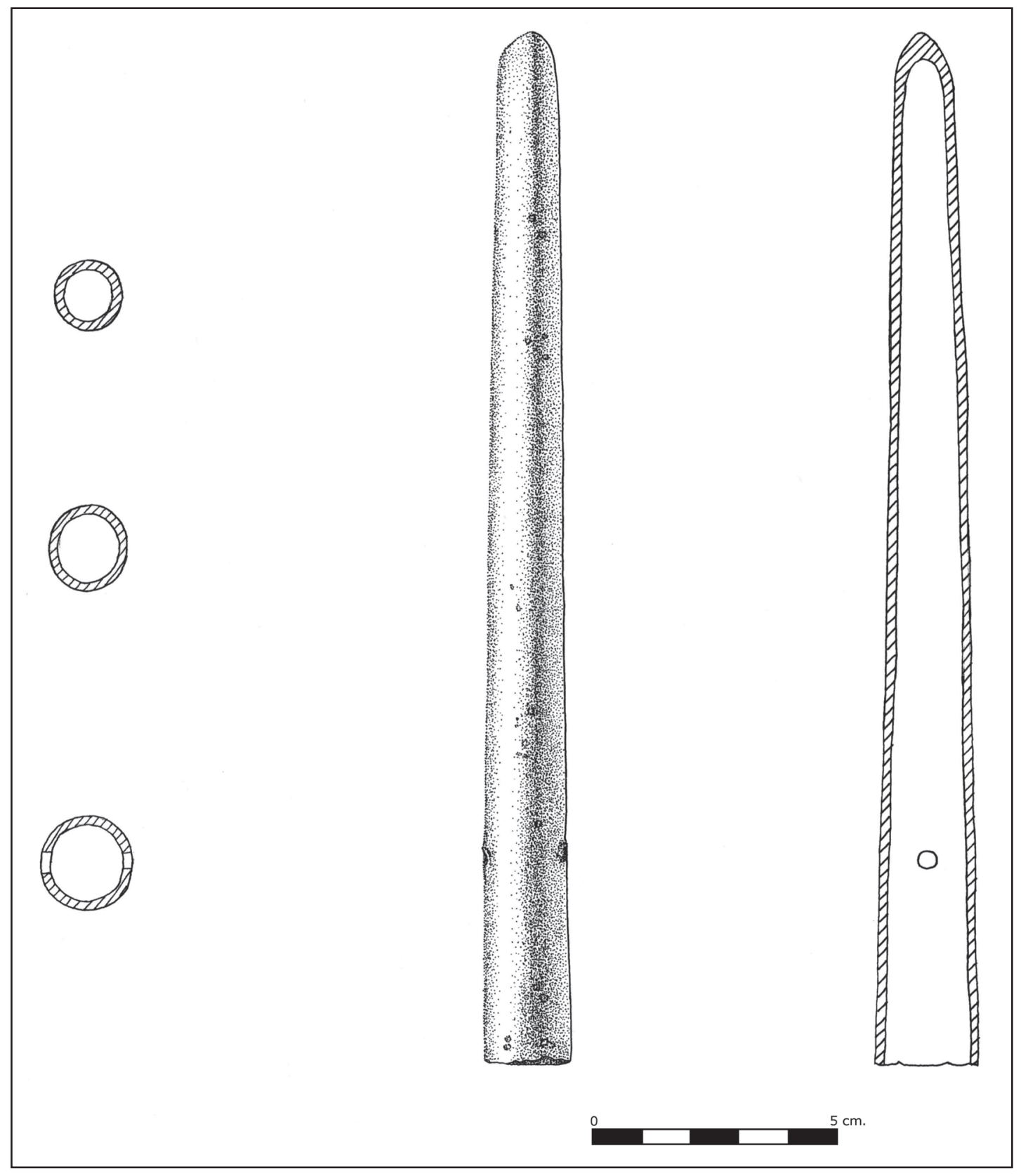

Figura 16. Regatón n. ${ }^{\circ} 15$.

N. ${ }^{\circ}$ 17: Fragmento de regatón (fig. 18)

Tipometría: longitud máxima: $54 \mathrm{~mm}$; diámetro máximo: $12 \mathrm{~mm}$; peso: $18 \mathrm{~g}$.

Extremo distal de un regatón tubular de punta roma y sección circular. 


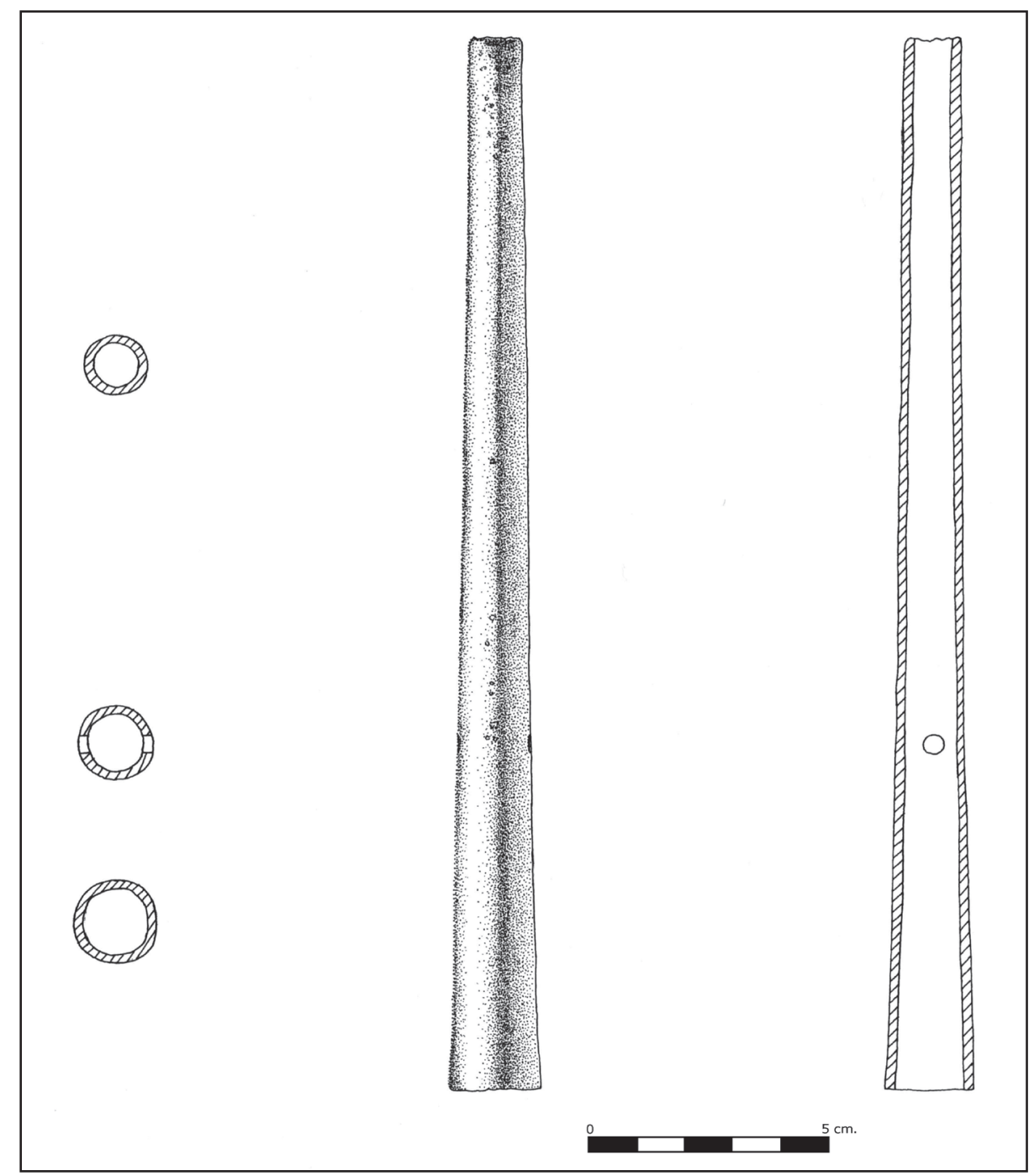

Figura 17. Regatón fragmentado n. ${ }^{\circ} 16$.

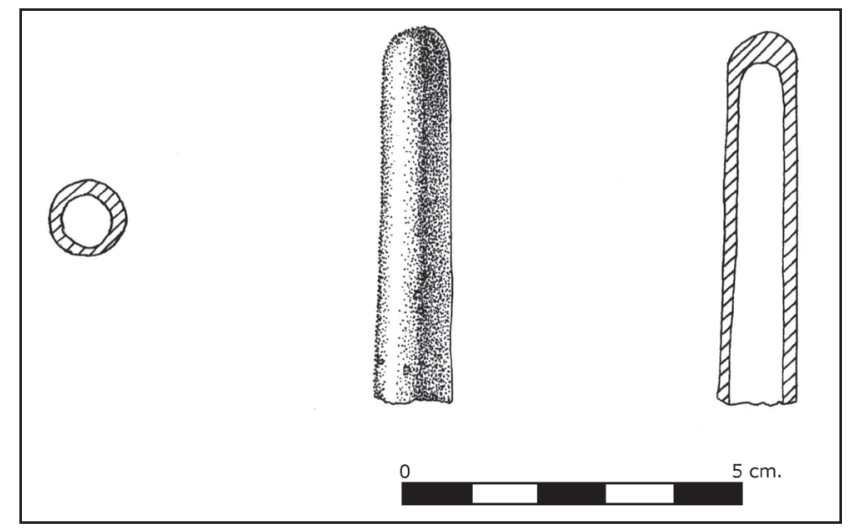

Figura 18. Fragmento de regatón n. ${ }^{\circ} 17$. 


\subsection{ANÁLISIS TIPOLÓGICO}

Los regatones, en general, no son piezas especialmente abundantes dentro de la metalurgia de la Edad del Bronce, siendo la Edad del Hierro el periodo de mayor difusión. En la Península Ibérica la mayor parte de los ejemplares recuperados proceden de la Ría de Huelva, mayoritariamente rematados en el extremo distal con un ensanchamiento tipo botón, como sucede también en los ejemplares portugueses o en los extremeños de Cabezo de Araya.

Los regatones peninsulares tipo chuzo, a los que pertenecen los de Grañón, son muy escasos, entre los que se cuentan los ejemplares meseteños de Valdevimbre (León), del BFI; Covaleda (Soria), del BFII (Fernández, 1986: 35); El Berrueco (Ávila) y, posiblemente, el fragmento del depósito de Puertollano (Montero y otros, 2002), ambos del BFIII. Sin embargo, ni por forma ni dimensiones están relacionados con los regatones de «Los Cascajos».

Los ejemplares de Grañón, uno de ellos completo (n. $\left.{ }^{\circ} 15\right)$ y otro fragmentado en la punta (n. $\left.{ }^{\circ} 16\right)$, ambos con una longitud superior a los $20 \mathrm{~cm}$, junto con el fragmento de punta $\mathrm{n}^{\mathrm{o}}$ 17 , son de desarrollo tubular y casi cilíndrico, similares a los largos bretones de la fase SaintBrieuc-des-Iffs, o a los ingleses de Guilsfield (Montgomeryshire), Congleton (Cheshire) y Caix (Almagro, 1940: 135).

Como sucede en el caso de las puntas de lanza de enmangue tubular, son objetos de escasa evolución formal y con una prolongada perduración cronocultural: en el caso británico, están presentes tanto en contextos del Bronce Medio, por ejemplo los de la fase Camerton-Snowhill de la región de Wessex, como en el Bronce Final, por ejemplo los del tesoro de Wilburton (Burgess y Colquhoun, 1988: 152), con los que los riojanos guardan una evidente similitud.

\section{ARQUEOMETALURGIA}

Catorce de los objetos metálicos integrantes del depósito de Grañón han sido sometidos a análisis no destructivo mediante microscopía electrónica de barrido (MEB) y análisis elemental por Rayos $\mathrm{X}^{2}$. Se trata, por lo tanto, de un método no destructivo que analiza la superficie del objeto, por lo que con carácter previo se procedió a la limpieza mecánica de las superficies a analizar con el fin de eliminar las pátinas y segregaciones propias del bronce (tabla 1).

De manera genérica, las espadas pistiliformes marcan el inicio de las aleaciones ternarias de cobre-estaño-plomo en el Bronce Atlántico, que alcanza su máximo desarrollo en el BFIII. Los motivos que llevaron a la adición intencionada de plomo en las coladas han sido ampliamente debatidos. Teniendo en cuenta que la incorporación de plomo a la aleación resta resistencia a las piezas, su introducción respondería a aspectos económicos, ya que estaría relacionada con intención de disminuir el porcentaje de cobre, cada vez más apreciado. Pero esta escasez de materia prima no es general a todas las regiones y, sin embargo, sí se generaliza la adición de plomo cuando en las regiones no deficitarias de cobre no debería ser necesario. Por otro lado, la incorporación de plomo cuenta con ventajas de tipo tecnológico, que pueden contrarrestar o compensar la pérdida de resistencia, ya que facilita la fundición del aleado, favorece el trabajo a buril en frío, y reduce el punto de fusión prolongando el estado líquido de las coladas, favoreciendo el uso de moldes más complejos.

Dentro del Bronce Atlántico es posible diferenciar ciertos grupos regionales relacionables con los diferentes periodos cronoculturales en base a los porcentajes de estaño y plomo, aunque las excepciones son abundantes, y no es raro comprobar cómo los porcentajes de la

2 Análisis realizados por el Laboratorio I+D de la Facultad de Químicas de la Universidad de Burgos. 


\begin{tabular}{|c|c|c|c|c|c|c|c|c|c|}
\hline & Objeto & $\mathrm{Fe}$ & $\mathrm{Ni}$ & Zn & As & Ag & Sn & Sb & $\mathbf{P b}$ \\
\hline \multirow{10}{*}{ 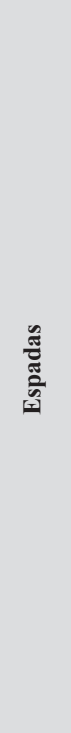 } & N. ${ }^{o} 1$ & 0.54 & 0.01 & - & 0.18 & 0.04 & 18.73 & 0.64 & 1.80 \\
\hline & N. ${ }^{\circ} 2$ & 0.46 & 0.09 & - & 0.15 & 0.14 & 15.85 & 0.62 & 0.62 \\
\hline & N. ${ }^{0} 3$ & 0.11 & 0.06 & - & 0.17 & 0.08 & 15.84 & 0.47 & 3.44 \\
\hline & N. ${ }^{\circ} 3$ & 0.03 & 0.12 & - & - & 0.09 & 5.88 & 0.34 & 1.21 \\
\hline & N. ${ }^{\circ} 4$ & 0.11 & 0.06 & - & 0.13 & - & 24.71 & 0.94 & 1.14 \\
\hline & N. ${ }^{\circ} 5$ & 0.04 & 0.07 & - & 0.18 & 0.15 & 16.68 & 0.70 & 1.13 \\
\hline & N. ${ }^{\circ} 8$ & 0.37 & 0.06 & - & 0.31 & 0.05 & 9.39 & 0.31 & 1.03 \\
\hline & N. ${ }^{\circ} 9$ & 0.58 & 0.06 & - & 0.27 & 0.01 & 8.48 & 0.31 & 2,91 \\
\hline & N. ${ }^{\circ} 10$ & 0.26 & 0.04 & - & 0.25 & 0.08 & 5.12 & 0.31 & 1.29 \\
\hline & N. ${ }^{\circ} 18$ & 0.23 & 0.12 & - & 0.64 & 0.15 & 13.32 & 0.70 & 1,43 \\
\hline \multirow{2}{*}{ 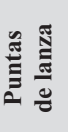 } & N. ${ }^{\circ} 11$ & 0.21 & 0.05 & - & 0.17 & 0.02 & 5.39 & 0.36 & 1.13 \\
\hline & N. ${ }^{\circ} 12$ & 0.64 & 0.04 & - & 0.25 & 0.01 & 11.50 & 0.54 & 0.22 \\
\hline \multirow{2}{*}{ 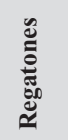 } & N. ${ }^{\circ} 15$ & 0.16 & 0.07 & - & 0.14 & 0.16 & 10.96 & 0.50 & 0.56 \\
\hline & N. ${ }^{\circ} 16$ & 0.26 & 0.07 & - & 0.10 & 0.15 & 16.03 & 0.72 & 1.72 \\
\hline
\end{tabular}

Tabla 1. Análisis químico del depósito de armas de Los Cascajos (Grañón, La Rioja).

composición química de los metales contradicen la datación estilística de las piezas, por lo que en la valoración cronológica deben primar los rasgos más significativos del objeto (Delibes et alii, 1999: 70).

En la submeseta Norte la proporción media de estaño en el Bronce Final se sitúa por encima del $12 \%$, mientras que el plomo aparece en proporciones del $1-4 \%$ en piezas escasamente plomadas, que no tienen una cronología más allá del 800 a.C., y entre el 4-8\% en las pertenecientes a la última centuria (ibíd.: 147).

La metalistería atlántica francesa es, en general, de bronces ternarios, con niveles en plomo en las espadas relativamente bajos, mientras que en las hachas son muy altos. También se observan diferencias geográficas, con niveles de plomo menos abundantes en los territorios interiores. En Aquitania hay una evolución hacia los bronces ternarios desde el BFI al BFII, con Saint-Denise- de-Pile en la transición con bronces binarios y ternarios (Rovira, 1995: 54-57). En los depósitos galos de Erondelle, Giraumont o Plainseau, en las regiones septentrionales de Oise y Somme, más de la mitad de las espadas pistiliformes están por debajo del 1\% de plomo (Bourhis, 1984: 40-41). En las Islas Británicas, aunque el añadido deliberado de plomo es característico del periodo Wilburton en el sur de Inglaterra, ya se da la tendencia hacia las aleaciones ternarias en los metales de Wessex. En general, estos porcentajes no suelen ser muy elevados, frecuentemente en torno al 2\% (Burgess y Coulquhoun, 1988: 142-145), 
considerado tradicionalmente el nivel mínimo compatible tanto con la intencionalidad como con la impureza.

Partiendo del origen británico de las piezas integrantes del depósito de Grañón, o al menos la empuñadura de espada . $^{\circ} 18$, los niveles de estaño son en general superiores al $10 \%$ en casi todos los casos, con varias piezas que superan el porcentaje medio del Bronce Atlántico estimado en el 15\%. Esta variación de porcentajes también se observa en las espadas inglesas, entre el 5 y el 13\%, aunque una gran mayoría se sitúa entre el 7 y el 9\% (ibíd.).

Con respecto al plomo, tanto en el depósito riojano como en muchas de las espadas británicas, se encuentra en un porcentaje en el límite de lo intencionado y de la impureza, como ya hemos visto en los depósitos galos. En Grañón el índice de plomo no suele superar el 2\%, aunque hay dos claras excepciones, una empuñadura (n. $\left.{ }^{\circ} 3\right)$, con $3,44 \%$, y una hoja de espada (n. ${ }^{\circ}$ 9), con 2,91\%, que se aproximan más a los índices del periodo Wilburton. Llama la atención el porcentaje muy inferior de la hoja $n .{ }^{\circ} 10$, atribuida a la empuñadura de espada $n .{ }^{\circ} 3$, $(1,29 \%)$, aunque no es un caso excepcional, ya que están constatadas variaciones similares de plomo entre la empuñadura y la hoja de una misma pieza, como sucede en la espada de Ses Salines de Mallorca (Rovira, 1995: 28).

Otro aspecto importante es el de la presencia de elementos químicos en forma impurezas, que, por lo tanto, no constituyen aleación. En la Península Ibérica estos elementos tienen una presencia muy escasa, a diferencia de otras zonas centroeuropeas o atlánticas, donde en ocasiones aparecen por encima del 0,5\% (Montero y otros, 2002: 19), como también sucede en Grañón.

En los bronces riojanos es muy significativo el elevado porcentaje de hierro, que llega incluso al $0,5 \%$. También son elevados los valores de níquel, arsénico, plata y antimonio, semejantes a los británicos y a los de la costa atlántica francesa. En este sentido, son de gran relevancia los análisis de los metales de Wilburton/Saint-Denise-de-Pile, que indican la posible existencia de una importante circulación de bronces centroeuropeos, con poco plomo y elevadas impurezas de arsénico, antimonio, níquel y plata, hacia dichas áreas, donde eran refundidos añadiéndoles estaño y plomo (Rovira, 1995: 54-57).

Con respecto a la manufactura metálica, aunque no se han realizado análisis metalográficos en este sentido, las fotografías mediante MEB de los planos las piezas apuntan a tratamientos mecánicos en frío, especialmente perceptibles en la empuñadura de espada $n .{ }^{\circ} 2$, en la hoja de espada $n .^{\circ} 9$, en el filo de la punta de lanza de enmangue tubular $n .^{\circ} 11$ y en el regatón n. ${ }^{\circ} 15$.

Durante el Bronce Final las cadenas operativas aplicadas al metal son muy variadas, aunque se conservan también las más básicas, como el simple moldeado. En este sentido son de gran interés los análisis realizados por Tylecote y Northover en espadas del Valle del Támesis, donde se observa que aunque la mayor parte son bronces forjados y posteriormente recocidos, también son frecuentes las piezas que conservan la estructura dendrítica de fundición, que no han sido sometidas a tratamientos mecánicos o térmicos posteriores al desmoldado, mientras que otras presentan tratamientos mecánicos específicos en los filos (Rovira, 1995: 49).

Un aspecto que caracteriza a prácticamente la totalidad de las piezas de Grañón son las numerosas pequeñas vacuolas visibles en la superficie, pero mayoritariamente en la sección de las piezas rotas. Esto es debido a que durante la fundición pueden liberarse burbujas de gas al contacto del metal caliente con el molde frío, que producen pequeños hoyos durante el proceso de enfriamiento. De hecho, uno de los mayores problemas que el artesano debe solucionar es el desgaseo del molde durante la colada de objetos masivos, como las hachas, puntas de lanza o espadas (Rovira, 2004: 33).

Por último, aunque el estado de conservación del bronce es muy bueno, son numerosas las huellas relacionadas con la etapa de destrucción premeditada de la mayor parte de las piezas (Quilliec, 2007: 105), patente en las numerosas muescas sobre la arista del filo de las 
espadas y de las puntas de lanza de enmangue tubular, producidas por la repetición reiterada de impactos; la torsión de la hoja de la empuñadura de espada . $^{\circ} 1$ y de las hojas n..$^{\circ} 8$ y 9; y el sometimiento a una fuente de calor de la zona de la guarda de las hojas $\mathrm{n}^{\circ}{ }^{\circ} 6 \mathrm{y} \mathrm{n} .^{\circ} 7$, con evidencias de post-fundición.

\section{CONTEXTUALIZACIÓN CRONOCULTURAL}

Uno de los rasgos culturales que más caracteriza a la Edad del Bronce es que a lo largo de este periodo, pero principalmente en su fase final, se ocultaron grandes cantidades de objetos metálicos integrantes de los denominados «depósitos». En la Península Ibérica ha sido recuperado un número de depósitos asociados al Bronce Atlántico muy inferior al resto del territorio europeo y, al contrario de lo que suele suceder en los países vecinos, en general se caracterizan por estar integrados por pocas piezas y contar con una escasa variedad tipológica (Ruiz-Gálvez, 1998: 269).

Las dieciocho piezas recuperadas del profuso depósito de Grañón, ya que en origen pesaba unos $50 \mathrm{~kg}$, se corresponden con elementos armamentísticos, espadas, puntas de lanza y regatones, objetos tradicionalmente asociados a las élites. Los depósitos metálicos peninsulares del Bronce Final conformados únicamente por armas cuentan por lo general con un número reducido de piezas, normalmente inferior a cinco. En el caso del depósito riojano, aunque los elementos conservados pertenecen exclusivamente a armas, según los testimonios de los donantes entre los objetos recuperados pudieron existir también elementos de adorno personal, tales como fíbulas y placas de cinturón. En los depósitos peninsulares es habitual que aquellos en que el número de piezas supere las diez no sean exclusivamente armamentísticos, exceptuando el depósito de puntas tubulares de Bembibre (León), integrado por veintinueve elementos, y el depósito de Puertollano (Ciudad Real), integrado por quince (Montero y otros, 2002: 26), por lo que el de Grañón estaría en esta línea, si se consideran válidos los citados testimonios. De hecho, según los informantes, la colección de piezas extraída estaba integrada también por yelmos y escudos, dos objetos que rara vez aparecen en depósitos (Kristiansen, 2001: 217), y desde luego nunca en la Península.

Por otro lado, aunque es frecuente que en los depósitos del Bronce Final existan numerosas piezas de un mismo tipo de objeto, como en el ya citado de Bembibre, el palentino de Cisneros, con cinco puntas de lanza, o el depósito de Huerta de Arriba (Burgos), con tres hachas, tres puñales y cuatro navajas, entre otros elementos; es excepcional la documentación de más de una espada, y cuando esto sucede no excede en número de dos, exceptuando algunos casos como el de la Ría de Huelva, el citado depósito de Puertollano o el depósito portugués de Casal dos Fiéis de Deus (Ávila, 2000). De hecho, la presencia de espadas en depósitos peninsulares es tan escasa que menos del $10 \%$ de las recuperadas proceden de este tipo de contexto cerrado (Meijide, 1988: 76).

Por lo tanto, la primera característica que confiere un valor excepcional al depósito de Grañón está en relación a la tipología y al número de piezas que lo integran: un número mínimo de diez espadas, si tenemos en cuenta que de los once fragmentos recuperados tan solo dos están asociados al mismo objeto; aunque esta cantidad, siempre según los testimonios aportados por los herederos de D. Vicente Murillo Murillo, fue en origen más elevada.

Una vez analizado el contenido general del depósito, quedan tres preguntas por responder: el origen de los objetos, su cronología y su significado. Con respecto a la primera de las cuestiones, es conocido que el Bronce Atlántico estaba conformado a partir de distintos centros regionales de producción de metales, unidos mediante el intercambio regular de sus productos, 
que a su vez estaban conectados con las redes centroeuropeas de intercambio. Esto implica que los metales, y particularmente las espadas y las lanzas, reproduzcan tendencias generales europeas, a las que hay que añadir las lógicas aportaciones locales (Kristiansen, 2001: 208). Sin embargo, como ya se ha visto en apartados anteriores, hay muy pocos datos que hablen de la procedencia foránea de los objetos recuperados en los depósitos peninsulares (Ruiz-Gálvez, 1998: 269), algo plenamente constatado en el depósito de Grañón.

En el análisis tipológico de los objetos ha quedado argumentada la excepcionalidad formal de las piezas, sobre todo empuñaduras de espada y regatones, con respecto a objetos similares recuperados en la Península Ibérica, con claro paralelismo con los tipos británicos y los de la fachada atlántica francesa.

El ejemplo más representativo es la empuñadura Erbenheim (n. $\left.{ }^{\circ} 18\right)$, inédita en la Península hasta la fecha, que en este caso es de tipo británico. Se trata de un ejemplar prácticamente idéntico a la espada Estratford recuperada en el río Lea, en el Valle del Támesis (Burgess y Colquhoun, 1988: . $^{\circ} 84$ ), que confirma su origen anglosajón, y encuadra cronológicamente el arma a finales del periodo Penard, entre 1200 y 1000 a.C., en el tránsito al periodo Wilburton; esto es, en el tránsito entre el BFI y BFII, fijando el terminus post quem del depósito.

También los regatones riojanos, excepcionales a nivel peninsular dentro de su tipología aunque con paralelos similares galos, están aún más estrechamente emparentados con los ejemplares británicos. El resto de las piezas, pero particularmente las empuñaduras de espada, están claramente relacionadas con las de estos territorios del occidente europeo, por lo que no se puede descartar que el depósito, antes de entrar en territorio peninsular, se viese incrementado con objetos de diferentes procedencias, tal y como apuntan determinados aspectos decorativos y los diferentes influjos tipológicos que coinciden en una misma pieza.

Este origen anglo-galo estaría en relación con el primer centro de intercambio atlántico del BFII, localizado en el sur de Inglaterra y en el noroeste de Francia. A partir de este ámbito geográfico, la red se amplió, incluyendo todo el frente atlántico, caracterizada por dos hechos: el impulso de la aleación del bronce y el estaño, y el influjo de los objetos metálicos de la fase tardía de la cultura de los Campos de Urnas, como las espadas Hemigkofen y Erbenheim. En estas circunstancias se produce una distribución de objetos de élite compuesto principalmente por espadas, calderos y ganchos de carne, distribuidos por la Europa atlántica mediante dos estrategias: a través del comercio de larga distancia de bienes de prestigio entre agrupaciones regionales de jefaturas, y a través de cadenas de intercambio de corta distancia, a lo largo de la Europa atlántica y con la Europa central, por las que circulaban variados objetos metálicos (Kristiansen, 2001: 208-209). Como sabemos, la Península Ibérica estaba incluida en esta amplia red de intercambio, con uno de los tres centros principales localizado en el noroeste, junto con los de sur de Inglaterra-Irlanda y noroeste de Francia, al que hay que sumar los circuitos regionales, como el meseteño, situado entre los cursos del Ebro y Tajo, en el que está integrado el ámbito geográfico de Grañón.

Con respecto al significado del depósito, la respuesta a esta pregunta está en el propio contexto geográfico y cultural en el que se produjo el hallazgo. Como se ha visto en apartados anteriores, fue localizado en la confluencia de una importante vía de comunicación — que ha evolucionado de calzada romana a Camino de Santiago, ruta de peregrinación y comercio de primer orden - con una vía pecuaria. Este último aspecto resulta fundamental, porque está constada arqueológicamente la existencia en este ámbito de rutas ganaderas desde la Prehistoria reciente. Se trata, pues, de un lugar de confluencia de vías naturales, una encrucijada de caminos, que en la mitología de numerosas culturas tiene elevada simbología. Los cruces de caminos están asociados a la idea del axis mundi, y simbolizan lugares de paso tanto físico como simbólico, representando la transición de un mundo a otro, de la vida a la muerte. Por 
este motivo, numerosas culturas han elegido las encrucijadas de caminos para la realización de depósitos votivos (Ruiz-Gálvez, 1995: 21-22).

Como sucede en Grañón, muchos de los depósitos broncíneos han sido localizados en pasos de montaña o cruces de caminos, como los asturianos de Gamonedo y Gumial, los burgaleses de Huerta de Arriba y Humada, los sorianos de Beratón y Covaleda, y los salmantinos de Peñaparda y Linares de Riofrío, entre otros (ibíd.: 25). Estos conjuntos son interpretados como depósitos de carácter profano, que reivindican los derechos de control de un punto estratégico por un líder, quien garantiza el libre paso y la seguridad, favoreciendo principalmente a las actividades comerciales (Ruiz-Gálvez, 1998: 270). Se trata, por lo tanto, de una zona neutral, un lugar intermedio físico y simbólico, en los que se conjuga una doble función, ritual y práctica.

Sin embargo, el hecho de que muchas de las piezas aparezcan fragmentadas premeditadamente y deterioradas por exposición a una fuente de calor, puede ser motivo de interpretación como depósito de chatarrero o de comerciante, como sucede en algunos de los documentados en la Bretaña. Esta primera explicación también se le ha dado al depósito de Villena, por estar integrado por piezas rotas o a medio facturar, aunque también por una vajilla completa, por lo que ha sido interpretado como un depósito de posesión personal. Precisamente por confluir ambas situaciones M. Ruiz-Gálvez (1995) lo interpreta como la amortización ritual de la posesión personal de un difunto de alto rango.

Otra circunstancia que sirve para disociar el depósito de Grañón con un depósito de chatarrero es la importante presencia de espadas que se cuentan entre sus piezas. Resulta difícil creer que un objeto con tanta carga simbólica como la espada pueda ser depositado únicamente como material para reciclar (Ávila, 2000: 30). Para Ruiz-Gálvez, los depósitos con piezas fragmentadas que contienen símbolos de prestigio para las elites, como el de Casal dos Fiéis de Deus, en la Extremadura portuguesa, son interpretados como depósitos de chatarra situados en encrucijadas, con el fin de conciliar el valor simbólico del depósito con su carácter utilitario (Ávila, 2000: 36). Sin embargo, la destrucción premeditada y el sometimiento de espadas a una fuente de calor, como sucede en «Los Cascajos», está constatado en depósitos fluviales británicos, como los de Wilburton y Duddingston (Bridgford, 1998), de claras connotaciones rituales.

La destrucción premeditada, como la que se observa en las piezas de Grañón, previa a las ofrendas de armas, es un aspecto ritual ya constatado y estudiado en la década de los cincuenta por H. J. Hundt (Meijide, 1988: 86). Por otro lado, el hecho de que las piezas aparecieran dispuestas ordenadamente, formando un emparrillado, y en un embolsamiento de ceniza, indica que el depósito estuvo acompañado de la celebración de algún tipo de ritual.

El depósito de Grañón es excepcional también dentro de su contexto geográfico, ya que se trata del único recuperado en la provincia de La Rioja. Culturalmente está enmarcado en la fase Cogotas I (1200-850 a.C), con área nuclear en la Meseta Norte, aunque el territorio riojano está incluido en el área de dispersión periférica del noreste del Valle del Ebro (Almagro, 1997: 221). Curiosamente, en el ámbito geográfico más inmediato al lugar del hallazgo, no se tiene constancia de la existencia de yacimientos con elementos vinculados a Cogotas I (Narvarte, 2001: 42), observándose en este sentido un amplio vacío en torno a las cuencas de los ríos Oja y Najerilla. Es en la zona de cabecera de este último río donde se localiza el yacimiento más próximo por el sur, «Majada Londeras», en Tobia, mientras que «Las Escaleras», en Sajazarra, en el norte, es el más próximo a la cuenca del Oja y también a Grañón. Este aislamiento geográfico viene a reafirmar la teoría antes expuesta sobre la interpretación de los depósitos en encrucijadas de caminos como lugares de intercambio o puntos de paso estratégico en territorio neutral. 


\section{BIBLIOGRAFÍA}

AвÁsolo, J. A. (1975): Comunicaciones de la época romana en la provincia de Burgos. Burgos, Diputación Provincial.

Almagro Basch, M. (1940): «El hallazgo de la ría de Huelva y el final de la Edad del Bronce en el Occidente de Europa». Ampurias, 2: 85-143.

Almagro Gorbea, M. (1976): «La espada de Entrambasaguas. Aportación a la secuencia de las espadas del Bronce en el Norte de la Península Ibérica», XL Aniversario del Centro de Estudios Montañeses, vol. III. Santander, Centro de Estudios Montañeses: 453-477.

Almagro Gorbea, M. (1997): «La Edad del Bronce en la Península Ibérica: periodización y cronología», Homenaje a Milagros Gil-Mascarell. Saguntum, 17: 217-229.

Ávila de Melo, A. (2000): «Armas, utensílios e esconderijos. Alguns aspectos da metalurgia do Bronze Final: o depósito do Casal dos Fiéis de Deus». Revista Portuguesa de Arqueologia, 3, 1: 15-120.

Barril, M.; Delibes, G. y Ruíz Zapatero, G. (1982): «Moldes de fundición del Bronce Final procedentes de El Regal de Pídola (Huesca)», Trabajos de Prehistoria, 39: 369-383.

Blázquez, J. M. y García-Gelabert, M. P. (1997): «El culto a las aguas en la Hispania prerromana», M. ${ }^{a}$ J. Peréx Agorreta (ed.), Termalismo antiguo. Actas del I Congreso Peninsular, Arnedillo (La Rioja). Madrid, Universidad Nacional de Educación a Distancia-Casa de Velázquez, pp. 105-115.

Bourhis, J. R. (1984): «Analyses des cuivres et bronzes de Picardie et du Nord de la France in Paléométallurgie de la France Atlantique. Age du Bronze (1)». Travaux du Laboratoire AnthropologiePréhistoire-Protohistoire-Quaternaire Armoricains Rennes: 23-43 .

Briard, J. (1965): Les Depots Bretons et L'Age du Bronze Atlantique. Rennes, Laboratoire d'Anthropologie Préhistorique de la Faculté des Sciences de Rennes.

Bridgford, S. (1998): «British Late Bronze Age Swords. The metallographic evidence», C. Mordant, M. Pernot y V. Rychner (dirs.), L'Atelier du bronzier en Europe du XXe au VIII siècle avant notre ère. II : Du minerai au métal, du métal à l'objet. Colloque Bronze' 96, Neuchâtel et Dijon, 1996. Paris, CTHS: 205-218.

Burgess, C. B. y Colquhoun, I. (1988): The swords of Britain. Prähistorische Bronzefunde IV, 5, München, Beck.

Cowen, J. D. (1951): «The Earliest Bronze Swords in Britain and Their Origins on the Continent of». Proceedings of the Prehistoric Society, XVII: 195-213.

Delibes, G.; Fernández, J.; Fontaneda, E. y Rovira, S. (1999): Metalurgia de la Edad del Bronce en el piedemonte meridional de la Cordillera Cantábrica. Salamanca, Junta de Castilla y León.

Fernández Manzano, J. (1986): Bronce Final en la Meseta Norte española: el utillaje metálico. Valladolid, Junta de Castilla y León.

Gaucher, G. y Mohen, J. P. (1972): Typologie des objets de L'Age du Bronze en France. I. Épées. Paris, Société Préhistorique Française. Commission du Bronze.

Gómez Soто, J. (2007): «Métallurgie atlantique et style céramique Rhin-Suisse-France orientale dans le Centre-Ouest de la France. A propos de l'épée pistilliforme de Saint-Hilaire-le-Palud (Deux-Sévres), un état de la question», C. Burgess, P. Topping y F. Lynch (eds.), Beyond Stonehenge: Essays on the Bronze Age in Honour of Colin Burgess. Oxford, Oxbow Books.

Kemenczei, T. (1988): Die Schewerter in Ungarn I. Prähistoriche Bronzefunde, IV, 6, München, Beck.

Kristiansen, K. (2001): Europa antes de la historia. Barcelona, Península.

Kytlicová, O. (2007): Jungbronzeitliche Hortfunde in Böhmen, Prähistoriche Bronzefunde, XX, 12, München, Beck.

Meijide Cameselle, G. (1988): Las espadas del Bronce Final en la Península Ibérica. Arqueohistórica, 1, Santiago de Compostela, Universidade.

Montero, I.; Fernández, M.; Gómez, B. y Ontalba, M. A. (2002): «Espadas y puñales del Bronce Final: el depósito de armas de Puertollano (Ciudad Real)». Gladius, XXII: 5-28.

Narvarte Sanz, N. (2001): «Cogotas I en el Valle Medio del Ebro. Estado de la cuestión en la provincia de La Rioja». Berceo, 140: 41-76.

Quilliec, B. T. (2007): «Vida y muerte de una espada atlántica del Bronce Final en Europa: reconstrucción de los procesos de fabricación, uso y destrucción», Complutum, 18: 93-107.

Rovira, S. (1995): «Estudio arqueometalúrgico del depósito de la Ría de Huelva». Ritos de paso y puntos de paso. La Ría de Huelva en el mundo del Bronce Final europeo. Complutum, n. ${ }^{\circ}$ extra 5: 33-58. 
RoviRA, S. (2004): «Tecnología metalúrgica y cambio cultural en la prehistoria de la Península Ibérica», Norba. Revista de Historia, 17: 9-40.

Ruiz-Gálvez, M. (1995): «Depósitos del Bronce Final: ¿sagrado o profano?, ¿sagrado y, a la vez, profano?», Ritos de paso y puntos de paso. La Ría de Huelva en el mundo del Bronce Final europeo. Complutum, n. ${ }^{\circ}$ extra 5: 21-32.

Ruiz-Gálvez, M. (1998): La Europa atlántica en la Edad del Bronce. Un viaje a las raíces de la Europa occidental. Barcelona, Crítica.

Recibido: 04/02/09

Aceptado: 20/02/09 